Portland State University

PDXScholar

Spring 7-5-2018

\title{
Differential Well-Being in Response to Incivility and Surface Acting among Nurses as a Function of Race
}

Lauren Sarah Park

Portland State University

Follow this and additional works at: https://pdxscholar.library.pdx.edu/open_access_etds

Part of the Nursing Commons, and the Psychology Commons

Let us know how access to this document benefits you.

\section{Recommended Citation}

Park, Lauren Sarah, "Differential Well-Being in Response to Incivility and Surface Acting among Nurses as a Function of Race" (2018). Dissertations and Theses. Paper 4480.

https://doi.org/10.15760/etd.6364

This Thesis is brought to you for free and open access. It has been accepted for inclusion in Dissertations and Theses by an authorized administrator of PDXScholar. Please contact us if we can make this document more accessible: pdxscholar@pdx.edu. 
Differential Well-Being in Response to Incivility and Surface Acting among Nurses as a Function of Race

by

Lauren Sarah Park

A thesis submitted in partial fulfillment of the requirements for the degree of

Master of Science

in

Psychology

Thesis Committee:

Larry Martinez, Chair

Jennifer Dimoff

Jason Newsom

Portland State University

2018 
(C) 2018 Lauren Sarah Park 


\begin{abstract}
Demand for healthcare services is rising dramatically as the proportion of older adults in the United States increases, and the success of these healthcare organizations depends on cooperation among patients, doctors, and nurses. These interpersonal interactions come with costs associated with managing one's emotions in ways that are in line with completing job tasks effectively, especially as past research has demonstrated that nurses are likely to experience and respond to incivility, and nurses of minority backgrounds even moreso. This study examines the effect of experiencing incivility on engaging in surface acting, or simulating emotions that are not actually felt; how these two factors influence well-being outcomes; and the impact of racial differences in these relationships. A sample of 100 Black and White nurses participated in this research. Results indicate that experiencing incivility increases emotional exhaustion both directly and indirectly through engaging in surface acting in response to incivility. Additionally, findings suggest that Black nurses are more likely than White nurses to experience incivility from other nurses. These results highlight how incivility can contribute to burnout and negative health outcomes and that this effect may be particularly salient among Black nurses.
\end{abstract}




\section{Table of Contents}

Abstract




\section{List of Tables}

Table 1: Inter-Item Correlations and Reliabilities for All Measures...................42

Table 2: Group Means and Standard Deviations for All Measures....................43

Table 3: Bootstrap Mediation Analyses for the Effect of Incivility on Well-Being Outcomes through Surface Acting.......................................44

Table 4: Bootstrap Conditional Indirect Effects Analyses for the Effect of Incivility on Well-Being Outcomes through Surface Acting as a Function of Race............45

Table 5: Independent Samples $t$-Tests on NIS Subscales by Race...................46

Table 6: NIS Subscale-Level Correlations with Outcome Variables..................47

Table 7: NIS Subscale-Level Bootstrap Mediation Analyses for the Effect of Incivility on Well-Being Outcomes through Surface Acting............................48

Table 8: NIS Subscale-Level Bootstrapped Conditional Indirect Effects Analyses for the Effect of Incivility on Well-Being Outcomes through Surface Acting as a

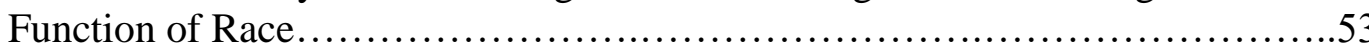


RACE AND WELL-BEING IN NURSING

List of Figures

Figure 1: Theoretical Model..................................................62 


\section{Introduction}

Nursing is the largest healthcare profession in the United States and has been the leading occupation for job growth in the country since 2008 (Health Resources and Services Administration, 2010). In addition to experiencing physical occupational hazards such as chronic pain and infectious disease, nurses often struggle with negative interpersonal interactions with physicians, supervisors, patients, and even other nurses. In fact, some estimates of incivility indicate that as many as nine out of 10 nurses reported experiencing verbal abuse at work (Winstanley \& Whittington, 2002). Nurses also must find a way to manage their self-presentation when faced with such interactions. Thus, this study aims to examine incivility in nursing; specifically, the utilization of surface acting in response to incivility, the negative health outcomes that may occur as a result, and how this relationship is impacted by race/ethnicity. First, I will use Tedeschi and Felson's (1994) theory of coercive actions to explain why incivility is common in the field of nursing, and describe outcomes of incivility for both the target and their organization, and I will define emotional labor and describe its outcomes and explain the hypothesized racial difference in engaging in surface acting. Third, I will discuss the methodology of this research. Fourth and finally, I will explain and elaborate upon this study's findings, paying particular attention to its limitations and implications for research and practice. 


\section{Incivility as Coercive Behavior}

Incivility is defined as behaviors with ambiguous intent to harm the target that are characteristically rude and discourteous (Cortina, Kabat-Farr, Leskinen, Huerta, \& Magley, 2013). The social interactionist perspective of Tedeschi and Felson's (1994) theory of coercive actions encompasses both the interpersonal and situational nature of incivility, and can explain why nurses are likely to experience, and engage in, incivility. Coercive actions can be defined as actions of violence or aggression with the intent of imposing harm that serve as functional components of social situations. These coercive actions have three major goals: (a) to control the behavior of others, (b) to restore justice, and (c) to assert and protect identities.

Unfortunately, the nursing profession is rife with uncivil behavior from a variety of sources, including managers, administrators, clinical instructors, charge nurses, staff nurses, and patients and their families (Etienne, 2014). Incivility is often used by both supervisors and nurses with the intention of controlling the behavior of others. In a qualitative study of 184 registered nurses, Simons and Mawn (2010) found that structural bullying, or unfair and punitive actions taken by supervisors, was a common form of uncivil behavior experienced by nurses. These unfair and punitive actions attempt to control the behavior of others through vindictive scheduling, restriction of sick and vacation time, undesirable and demanding patient assignments, and overwhelming workload. Gaffney and colleagues (2012) also found that nurses often experienced incivility through others controlling their patient assignments and workload, such as 
assigning nurses multiple extremely difficult cases, or assigning more patients than the nurse can handle at one time.

Incivility in order to restore justice has been empirically demonstrated as well outside the field of nursing. In a longitudinal study on the likelihood of instigating uncivil behaviors, Blau and Andersson (2005) found that experiencing distributive injustice led to a higher likelihood of perpetrating incivility in working adults. In the name of justice, incivility itself may beget further incivility, a phenomenon called an "incivility spiral" (Andersson \& Pearson, 1999). Reich and Hershcovis (2015) conducted two experiments whose findings supported the concept of the incivility spiral; across the experiments, observers of incivility tended to punish incivility instigators by giving them undesirable tasks and providing negative performance evaluations. There is some evidence for the potential for an incivility spiral within nursing, as research has shown that acts of bullying promote a sense of normalization of bullying in nursing teams (Hutchinson, Wilkes, Jackson, \& Vickers, 2010). Additionally, a qualitative study of nurses by Hutchinson, Vickers, Wilkes, and Jackson (2009) demonstrated that uncivil behavior was often rewarded by the organization through network advantages, promotions, or financial gain through increased income and retirement benefits. The increased normalization of bullying in work teams and structural rewards given to those who perpetuate incivility are likely to promote an incivility spiral in nursing, where nurses who experience incivility view the behavior as acceptable or even favorable in their organizations.

Finally, incivility with the intent of asserting or protecting identities is common in nursing due to disparate levels of power. Some researchers have hypothesized that 
because nurses can be considered an oppressed group due to the fact that they are controlled by external forces (e.g., physicians, supervisors, and patients), nurses may engage in incivility toward one another due to their need for power (Roberts, 1983). Nurse-to-nurse hostility, or horizontal bullying, can thus be viewed as a form of oppressed group behavior (Etienne, 2014); for example, a nurse who lacks the power to respond effectively to a hospital administrator may displace her hostility toward another nurse (Dollard, Doob, Miller, Mowrer, \& Sears, 1939). Additionally, nurses may engage in incivility to protect their professional identities. In a 2010 study of Turkish nurses, Katrinli, Atabay, Gunay, and Cangarli examined nurses' perceptions of factors that influence horizontal bullying and found that participants named negative performance appraisals, decisions about organizational structure, and equipment allocation as reasons for nurse-to-nurse hostility (Katrinli, Atabay, Gunay, \& Cangarli, 2010). These findings indicate that nurses may bully others in order to negatively affect the performance of others and positively affect their own performance, thus protecting their professional identity.

\section{Selective Incivility and the Influence of Race}

For nurses who belong to groups that have been historically marginalized (e.g., racial or ethnic minorities), this lack of social power further influences the likelihood of being the target of incivility. Cortina, Magley, Williams, and Langhout (2001) found that those with less social power, such as racial minorities and women, are at higher risk for experiencing mistreatment than those with more social power. The theory of selective incivility underlies this finding, stating that incivility can act as a covert, modern 
manifestation of gender and racial discrimination (Cortina, 2008), and engaging in selective incivility against members of an outgroup may serve as an attempt to protect one's own identity.

Empirical research has supported the claim that target attributes influence the likelihood of experiencing incivility. Lim and Lee (2011) found that younger workers were more likely to experience workplace incivility than older workers. Research that examines the association between gender and incivility has shown contradictory findings; Lim and Lee (2011) found that men report higher frequencies of uncivil behavior than women, and Cortina et al. $(2001 ; 2013)$ found that women report more uncivil encounters than men. Cortina et al. (2013) found that belonging to a racial minority was associated with more frequent experiences of incivility, and Black women in particular reported more uncivil treatment than other groups. Indeed, Simons and Mawn (2010) found that incivility in nursing often occurs based on the target's level of education or ethnicity; an Asian nurse indicated that her English pronunciation is often ridiculed by her coworkers. Given that Black individuals make up the largest racial minority group in the registered nurse population (American Association of Colleges of Nursing, 2015), the present research will focus on racial differences, specifically those between Black and White nurses, in experienced incivility. Thus, I predict the following:

Hypothesis 1: Black nurses will experience more incivility than their White counterparts.

The literature has consistently demonstrated that workplace incivility produces negative outcomes for both the organization and the target of incivility. At the 
organizational level, incivility causes both intentions to turnover (Wilson, Diedrich, Phelps, \& Choi, 2011) and turnover itself (Rosenstein \& O’Daniel, 2005), possibly due to increased burnout (Thomas, 2003). Simons (2008) found that as the frequency of incivility increased, so did the likelihood of nurses leaving their organizations.

Additionally, employees may respond to incivility in the workplace by withdrawing from work, especially if changing jobs or careers is not a viable option (Sliter, Sliter, \& Jex, 2012).

At the individual level, being the target of incivility produces negative outcomes in both job attitudes and individual health. Research has demonstrated that being the target of incivility results in lower job satisfaction (Spence Laschinger, Leiter, Day, \& Giln, 2009; Rowe \& Sherlock, 2005) and organizational commitment (Spence Laschinger et al., 2009). In addition to these job-related individual outcomes, targets of incivility suffer from negative health outcomes, including impaired sleep (Felblinger, 2009), poor mental health (Cortina et al., 2001; Björkqvist, Österman, \& Hjelt-Bäck, 1994), lower levels of energy (Giumetti et al., 2013) and even symptoms of post-traumatic stress (Felblinger, 2008). Thus, I predict the following:

Hypothesis 2: Incivility will be negatively related to perceptions of health $(H 2 a)$, sleep quality $(H 2 b)$, sleep quantity $(H 2 c)$, and emotional valence $(H 2 d)$, and positively related to emotional exhaustion $(H 2 e)$. 


\section{Emotional Labor and Surface Acting}

Past research has demonstrated that experiencing incivility can result in heightened emotional labor (Adams \& Webster, 2011; Sliter, Jex, Wolford, \& McInnerney, 2010). Emotional labor is defined as the process of regulating both feelings and expressions for organizational goals (Grandey, 2000). Organizations often hold explicit or implicit display rules in order to enforce certain emotional expressions as a means of attaining organizational objectives (Ashforth \& Humphrey, 1993; Rafaeli \& Sutton, 1989). These emotional expectations of employees are often viewed as job requirements by both employees and their supervisors, and are common in frontline occupations such as education, customer service, and healthcare (Brotheridge \& Grandey, 2002).

Although employees may be expected to express solely positive emotions and suppress negative emotions, this regulation is not always possible. There are likely instances in which these emotions may not genuinely be felt, and the employee must instead express the emotion without actually feeling it. Simulating emotions that are not actually felt is called surface acting (Hochschild, 2012), and is very common in the nursing profession (Yang \& Chang, 2008). This concept is similar to impression management, or the process by which people control the impressions others form of them, but is distinct in its reactivity. While impression management is the manipulation of one's outward physical and emotional expressions to control others' impressions and does not require the presence of an antecedent event, surface acting is the manipulation of one's outward emotional reaction to a specific antecedent event. By contrast, deep acting 
refers to attempting to actually experience the emotion that one wishes to portray, rather than only manipulating one's outward expression (Hochschild, 2012). Past research has demonstrated that deep acting requires less emotional labor and cognitive effort and yields fewer negative outcomes and more positive outcomes than surface acting (Hülsheger \& Schewe, 2011; Mann \& Cowburn, 2005; Totterdell \& Holman, 2003; Brotheridge \& Grandey, 2002). Additionally, perceptions of negative interactions are strongly positively related to surface acting and only weakly related to deep acting (Grandey, Dickter, \& Sin, 2004; Sliter, Jex, Wolford, \& McInnerney, 2010). When compared to deep acting, surface acting is more detrimental to the actor and is more likely in cases of negative interactions such as incivility; as such, I only examine surface acting in this research.

Outcomes of surface acting are generally negative and occur at both the organizational and individual levels. Surface acting has been empirically linked to withdrawal behaviors, including leaving the work floor, missing work, and turnover (Grandey, 2000). Additionally, emotional regulation can impair cognitive performance (Baumeister, Bratslavsky, Muraven, \& Tice, 1998; Richards \& Gross, 1999). Finally, surface acting affects customer or patient service performance (Grove \& Fisk, 1989; Rafaeli \& Sutton, 1987) because when people surface act observers can often detect the deception (Ekman \& Friesen, 1969). Individual-level outcomes include increased burnout (Grandey, 2000), decreased job satisfaction (Abraham, 1998; Morris \& Feldman, 1997), and increased emotional exhaustion (de Jonge, Le Blanc, Peeters, \& Noordam, 2007). Additionally, there is evidence in the literature that emotion suppression is related to 
sympathetic activation of the cardiovascular system (Gross \& Levenson, 1997), which, in turn, is associated with poor physical health (Pennebaker, 1990). Due to the impacts of surface acting and incivility on health outcomes, I hypothesize the following:

Hypothesis 3: There will be an indirect effect of incivility on perceptions of health $(H 3 a)$, sleep quality $(H 3 b)$, sleep quantity $(H 3 c)$, and emotional valence $(H 3 d)$, and emotional exhaustion $(H 3 e)$ through surface acting.

\section{Group Differences in Surface Acting}

Past research on emotional labor has examined group differences in the contexts of age and gender. Dahling and Perez (2010) found that the age of service employees was positively correlated with deep acting and negatively correlated with surface acting. This finding indicates that younger employees were more likely to engage in surface acting than deep acting when engaging in emotional labor, and older employees were more likely to engage in deep acting than surface acting. In a study by Kruml and Geddes (2000), women were found to be more likely than men to report they felt differently than their expression conveyed. Furthermore, Johnson and Spector (2007) found that surface acting in women led to greater emotional exhaustion, poorer affective well-being, and lower job satisfaction than surface acting in men.

One relationship that has yet to be quantitatively examined is that of race and emotional labor, though a few studies have either theorized about this relationship or qualitatively examined it. The only study that has empirically examined race and emotional labor was conducted by Evans (2012). Through qualitative interviews with Black pilots and flight attendants, this research demonstrated that Black individuals do 
experience highly regulated emotional labor. However, this research did not compare Black airline employees with White airline employees, so differential emotional labor by race could not be examined. Citing social psychological theories, Hewlin (2003) hypothesized that members of minority groups may display certain emotions to fit in and receive the same benefits as their majority group counterparts. Moreover, individuals from a minority background may manage their impressions in order to seem as competent and non-threatening as those in the majority group (Hewlin, 2003). Nevertheless, these hypotheses were not empirically tested.

The present research aims to expand on these past findings by empirically examining the difference in surface acting between White and Black nurses. Because the literature has shown increased risks of both incivility and surface acting for individuals with minority backgrounds, and these have empirically demonstrated negative health outcomes, I hypothesize the following:

Hypothesis 4: The indirect effect between incivility and well-being through surface acting will be moderated by race such that Black nurses will engage in more emotional labor in response to incivility than their White counterparts (see Figure 1). 


\section{Method}

\section{Participants}

Participants were actively recruited from nursing organizations in the United States and through snowball sampling, but also assured their participation was voluntary. Interested nurses completed a recruitment survey in which they indicated their consent to participate in the research study. The survey collected information about the participants' workplaces, including current job role (licensed practical nurse, registered nurse, or nurse practitioner), their workplace setting (hospital, doctor's office, nursing home), and the number of hours they work per week. Demographic data were also collected, including race, gender, and age. Only those who met the following criteria were included in the random selection of participants: (a) work mostly in direct contact with patients, (b) work 30 or more hours per week, and (c) identify as female ${ }^{1}$. From this recruitment pool of 186 nurses, a total of 100 nurses (51 Black, 49 White) were randomly selected to participate in the survey. Participants were compensated up to $\$ 50$ in order to improve response rates and reduce attrition as part of a larger longitudinal study, as well as thank them for their time in the study.

\section{Measures}

Incivility. Incivility was measured using Guidroz, Burnfield-Geimer, Clark, Schwetschenau, and Jex's (2010) Nursing Incivility Scale (NIS; see the Appendix for all study items). The scale contains 37 items across eight subscales, measuring source-

\footnotetext{
${ }^{1}$ Only one male-identifying nurse offered to participate in this study.
} 
specific behaviors (i.e., incivility from nurses, supervisors, physicians, and patients) as well as general incivility. Agreement was reported on a 5-point Likert-type scale ranging from 1 (agree not at all) to 5 (strongly agree). A sample item from this scale is "Nurses bad-mouth others in the workplace." Reliability for the total scale was $\square=.95$, and subscale reliabilities ranged from $\square=.81$ to $\square=.94$. Hypothesis-driven statistical analyses will include a composite variable for the total scale, rather than each subscale.

Surface acting. Surface acting was measured using Brotheridge and Lee's (2003) three-item surface acting scale. Participants indicated how frequently they performed certain behaviors on an average day at work on a Likert-type scale ranging from 1 (never) to 5 (always). A sample item from this scale is "How frequently do you pretend to have emotions you didn't really have?" Reliability for the scale was $\square=.74$.

Health. Health was measured with one item from the 2002 World Health Survey (Subramanian, Huijts, \& Avendano, 2010): “In general, how would you rate your health today?" Participants rated their health on a Likert-type scale ranging from 1 (very bad) to 7 (very good). In outlining best practices for collecting self-rated health $(\mathrm{SRH})$ in surveys, Lee (2015) recommended asking about participants' health using a single global item rather than multiple items concerned with different health domains. Using measures regarding specific health domains could limit understanding of overall health as these measures together may still capture a narrower aspect of health than that of a single global health item (Maddox \& Douglass, 1973; Mossey \& Shapiro, 1982; Verbrugge \& Ascione, 1987). As such, a single global health item provides better construct validity than multiple items assessing different facets of health. 
Sleep. Sleep quality and quantity were measured with the Pittsburgh Sleep Quality Index (PSQI; Buysse, Reynolds, Monk, Berman, \& Kupfer, 1989) and five items developed for the current study. The PSQI is a one-item measure that asks participants to evaluate last night's sleep on a scale from 1 (very bad) to 10 (very good). Participants then indicated how many hours they slept last night and indicated their agreement with 4 items describing common sleep issues on a Likert-type scale ranging from 1 (strongly disagree) to 5 (strongly agree). A sample item from this sleep measure is, "I woke up after my usual amount of sleep feeling tired and worn out." Reliability for the four sleep issues items was $\square=.83$. For the purpose of this study, sleep served as an objective proxy for physical health in the absence of biological or physiological measures.

Emotional valence. Emotional valence was measured with 16 items from the Job-Related Affective Well-Being Scale (JAWS; Van Katwyk, Fox, Spector, \& Kelloway, 2000). Participants indicated the extent to which they were experiencing certain emotions on a Likert-type scale ranging from 1 (not at all) to 5 (very much). The list of emotions includes "depressed," "calm," "excited," and "anxious." Reliability for this scale was $\square=.79$. Though debate exists as to whether emotional valence is a consistent trait or a fluctuating state, emotional valence is treated as a state variable in this study; items from the JAWS were worded such that participants indicated their experience of each emotion in the present moment.

Emotional exhaustion. Emotional exhaustion was measured using six items from two separate scales: three items from the Maslach Burnout Inventory (MBI; Maslach \& Jackson, 1981) and three reverse-coded items from the vitality subscale of the Thriving at 
Work Scale (Porath, Spreitzer, Gibson, \& Garnett, 2012). For each item, participants indicated the extent to which they were experiencing a certain emotional state on a Likert-type scale ranging from 1 (not at all) to 5 (very much). A sample item from this measure is, "I feel emotionally drained." Reliability for the total set of items was $\square=.91$. 


\section{Results}

\section{Hypothesis Tests}

Hypothesis 1. Hypothesis 1 stated that Black nurses would experience significantly more incivility than their White counterparts. Because Levene's test of unequal variances was significant, $(F(1,98)=6.01, p<.05)$, I conducted a betweensubjects $t$-test comparing White and Black nurses' incivility composite variable using Welch's correction. There was no significant difference between White nurses $(M=2.01$, $S D=0.51)$ and Black nurses $(M=2.18, S D=0.73)$ with regard to experienced incivility, $t(89.68)=1.33, p=.19$, Cohen's $d=0.27$. Though the mean scores for incivility were in the expected direction, Hypothesis 1 was not supported. Means by racial group and across racial groups can be found in Table 1.

Hypothesis 2. In order to test Hypothesis 2, that incivility would be significantly related to well-being outcomes, I examined the Pearson's $r$ correlations between incivility and health, sleep quality and quantity, emotional valence, and emotional exhaustion. Pearson correlation coefficients between all variables of interest can be found in Table 2 . Incivility was significantly negatively correlated with perceptions of health, sleep quality, sleep quantity, and emotional valence, and significantly positively correlated with emotional exhaustion. Because incivility significantly correlated with all of the wellbeing outcomes of interest, Hypotheses $2 a-e$ were fully supported.

Hypothesis 3. Hypothesis 3 stated that there would be an indirect effect of incivility on well-being outcomes (perceptions of health, sleep quality and quantity, emotional valence, and emotional exhaustion) through surface acting. These 
hypothesized relationships were examined using Hayes' PROCESS Macro Model 4 (Hayes, 2013) for indirect effects, with incivility as the independent variable and surface acting as the mediator. For all analyses using Hayes' PROCESS Macro (Hayes, 2013), percentile bootstrap confidence intervals using 1,000 samples are reported.

Perceptions of health. In Step 1 of the hypothesized mediation model with perceptions of health as the outcome variable, the direct effect of perceptions of health on incivility, ignoring the mediator, was not significant, $b=-0.22, \beta=-0.11,95 \% \mathrm{CI}=[-$ $0.62,0.19]$. Step 2 showed that the regression of perceptions of health on the mediator, surface acting, was significant, $b=-0.42, \beta=-0.25,95 \% \mathrm{CI}=[-0.77,-0.07]$. Step 3 of the mediation process showed that the mediator (surface acting), was significantly predicted by incivility, $b=0.46, \beta=-0.40,95 \% \mathrm{CI}=[0.25,0.67]$; this result remained consistent across outcomes. As such, Hypothesis 3a was not supported.

Sleep quality. In testing the hypothesized mediation model with sleep quality as the outcome variable, the regression of sleep quality on incivility, ignoring the mediator, was significant, $b=-1.09, \beta=-0.39,95 \% \mathrm{CI}=[-1.65,-0.53]$. Results showed that the regression of sleep quality on the mediator, surface acting, was not significant, $b=-0.27$, $\beta=-0.11,95 \% \mathrm{CI}=[-0.75,0.22]$. The indirect effect of incivility through surface acting on sleep quality was not significant, $b=-0.12,95 \% \mathrm{CI}=[-0.35,0.11]$. Thus, Hypothesis 3b was not supported.

Sleep quantity. The direct effect of incivility on sleep quantity disregarding the mediator was significant, $b=-0.89, \beta=-0.34,95 \% \mathrm{CI}=[-1.42,-0.35]$. Sleep quantity was not significantly predicted by the mediator, surface acting, $b=-0.02, \beta=-0.01,95 \%$ 
$\mathrm{CI}=[-0.49,0.44]$. The indirect effect of incivility through surface acting on sleep quantity was also not significant, $b=-0.01, \beta=-0.04,95 \% \mathrm{CI}=[-0.28,0.23]$. Hypothesis 3c was not supported.

Emotional valence. The direct effect of incivility on emotional valence was significant, $b=-0.53, \beta=-0.41,95 \% \mathrm{CI}=[-0.78,-0.28]$. Emotional valence was not significantly predicted by surface acting, $b=-0.16, \beta=-0.14,95 \% \mathrm{CI}=[-0.37,0.06]$. As such the indirect effect of incivility on emotional valence through surface acting was not significant, $b=-0.07, \beta=-0.06,95 \% \mathrm{CI}=[-0.19,0.04]$. These results do not provide support for Hypothesis $3 \mathrm{~d}$.

Emotional exhaustion. The direct effect of incivility on emotional exhaustion was significant, $b=0.68, \beta=-0.41,95 \% \mathrm{CI}=[0.37,0.99]$. Emotional exhaustion was also significantly predicted by the mediator, surface acting, $b=0.30, \beta=-0.21,95 \% \mathrm{CI}=$ $[0.03,0.57]$. The indirect effect of incivility on emotional exhaustion through surface acting reached significance, $b=0.14, \beta=-0.08,95 \% \mathrm{CI}=[0.01,0.28]$. For emotional exhaustion, these results provide support for the indirect effect model predicted in Hypothesis $3 \mathrm{e}$.

Hypothesis 4. Hypothesis 4 stated that the indirect relationships between incivility, surface acting, and well-being outcomes would be moderated by race such that Black nurses would engage in more emotional labor in response to incivility than their White counterparts. In order to test these hypotheses, I used Hayes’ PROCESS Macro Model 7 (Hayes, 2013) for conditional indirect effects, with incivility as the independent variable, surface acting as the mediator, and race as the moderator. The results of these 
analyses are displayed in Table 4 . The relationship between race and surface acting and the relation between the interaction of race and incivility were not significant for the well-being outcomes of perceptions of health, sleep quality, sleep quantity, and emotional valence. For emotional exhaustion, the moderation of race was significant for both Black and White nurses; however, the difference between Black and White nurses was not significant according to the index of moderated mediation, $b=0.03, \beta=-0.02,95 \% \mathrm{CI}=$ $[-0.11,0.20]$. As such, Hypothesis 4 was not supported across all five outcomes.

\section{Exploratory Analyses}

Because the NIS (Guidroz et al., 2010) is comprised of multiple source- and behavior-specific subscales, I conducted exploratory analyses to examine how different sources and types of incivility may differentially impact nurses based on race. In exploring these relationships for Hypothesis 1, conducted independent samples $t$-tests using the source-specific subscales and found that there were indeed significant differences between Black and White nurses in experiencing a variety of types of incivility (see Table 5). Levene's test for equality of variances was significant for each of the following results, so the adjusted statistics are reported.

In terms of general incivility, Black nurses $(M=1.95, S D=1.06)$ were more likely than White nurses $(M=1.48, S D=0.56)$ to experience inappropriate jokes regarding facets of one's identity, including religion, race, gender, and sexual orientation, $t(76)=2.76, p<.01$, Cohen's $d=0.55$. Black nurses $(M=2.74, S D=0.97)$ were also more likely to experience hostile forms of incivility, including yelling and arguing, than White nurses $(M=2.28, S D=0.67), t(89)=2.76, p<.01$, Cohen's $d=0.55$. 
Nurses also differed by race when examining types of incivility experienced from other nurses. Black nurses $(M=1.66, S D=0.80)$ were more likely than White nurses $(M$ $=1.31, S D=0.45)$ to experience incivility from nurses in the form of inconsiderate behavior, such as screaming and arguing, $t(80)=2.68, p<.01$, Cohen's $d=0.54$. Additionally, the likelihood of experiencing free-riding behaviors (e.g., another nurse taking credit for one's work) was significantly higher for Black nurses $(M=2.44, S D=$ 1.21) than White nurses $(M=1.67, S D=0.80), t(87)=3.81, p<.01$, Cohen's $d=0.75$. There were no significant differences between Black and White nurses in terms of incivility from supervisors, physicians, or patients and visitors, all $t \mathrm{~s}(98)<1.50$, all $p \mathrm{~s}>$ .10. Together, these results suggest that Hypothesis 1 was partially supported.

For Hypothesis 2, I examined the Pearson's $r$ correlations of subscale-level mean incivility scores with surface acting and the well-being outcomes of interest (see Table 6). Findings indicated that both general hostility and rudeness and incivility from physicians were significantly correlated with surface acting and all well-being outcomes. By contrast, correlations including free-riding behaviors from other nurses did not reach significance. Thus, Hypothesis 2 was fully supported for general hostile and rude behaviors and incivility from physicians.

Subscale-level analyses for Hypothesis 3, the indirect effect model, yielded different results depending on the source of the incivility (see Table 7). Surface acting, the mediator, was significantly predicted only by general incivility, physician incivility, and incivility from patients and visitors. Within these particular subscales, the indirect 
effect model was supported only for the well-being outcomes of emotional valence and emotional exhaustion. These results provide mixed support for Hypothesis 3.

Finally, subscale-level analyses were conducted for Hypothesis 4, the indirect effect model with a moderation of the nurses' racial identity. The addition of this moderation was not supported across subscales (see Table 8). However, while the index of moderated mediation was not significant for all analyses, a racial difference did indeed emerge in the magnitude of the indirect effect, such that the bootstrapped $95 \%$ confidence intervals surrounding the indirect effect estimate did not cross zero for Black nurses in most cases but did for White nurses in most cases. This suggests that the links between incivility and most outcomes were mediated by surface acting for Black, but not for White nurses, lending mixed support for Hypothesis 4. 


\section{Discussion}

Results from this study suggest that experiencing incivility has negative implications for well-being. However, the mechanisms through which incivility influences these outcomes differed in this sample, and the hypothesized influence of race was not supported. There was not a significant difference between Black and White nurses in experiencing incivility, failing to support Hypothesis 1 . This is perhaps due to the fact that, according to past research, members of minority groups are more reluctant to report their own experiences with discrimination than acknowledge their group experiences discrimination as a whole (Crosby, 1982; Crosby et al., 1989). The lack of support for Hypothesis 1 could be due to this pattern of under-reporting. Additionally, while incivility within nursing as a whole is a high base rate phenomenon, average scores on the Nursing Incivility Scale in this sample were lower than those of past research (Guidroz et al., 2010). As such, this lack of racial difference could be due to a lack of experiencing incivility across nurses in both groups. Finally, these results may be subject to a survival bias, where only nurses who have had positive workplace experiences remained long enough in the profession to participate in this study.

This overall finding is qualified by significant differences between Black and White nurses when examining source- and behavior-specific incivility. Specifically, Black nurses were significantly more likely to experience inappropriate jokes about facets of one's identity and hostile behavior. When examining incivility from other nurses, this pattern held true for inconsiderate behaviors and free-riding. As such, within this sample, selective incivility was more likely to occur from another nurse than any 
other source. This finding supports the theoretical framework of Tedeschi and Felson's (1994) theory of coercive actions; specifically, that nurses may act uncivilly toward one another due to a need to protect their identities, restore justice, and maintain social power. Nurses with less social power due to their minority racial identity experienced more of this uncivil behavior than their majority counterparts.

Although incivility was indeed significantly related to the well-being outcomes of interest in this study, its impact on these outcomes through surface acting was not supported in the hypothesized indirect effect model. It is possible that mediating mechanisms not examined in this study explain this relationship. For example, rumination, or a preoccupation with and repetitive thoughts of an event or common theme (Martin \& Tesser, 1996), could explain why incivility relates to the well-being outcomes in this study. Past research has demonstrated that the relationship between workplace incivility indirectly and negatively affects sleep through increased negative work rumination (Demsky, Fritz, Hammer, \& Black, 2018; Bayne, 2015). Similarly, Baranik, Wang, Gong, and Shi (2014) found that the relationship between incivility from customers and well-being and emotional exhaustion was mediated by cognitive rumination. Increased negative affect could also explain this relationship, and past research has demonstrated that negative emotions mediate the effect of experienced incivility on burnout, or emotional exhaustion (Zhou, 2014).

However, exploratory analyses using the behavior- and source-specific subscales of the NIS indicated that there were differences in this finding between subscales. General incivility in the form of inappropriate jokes and hostility, as well as incivility 
from physicians and patients, significantly predicted surface acting in the indirect effect model. This finding indicates that surface acting may be more likely when experiencing incivility from individuals outside of one's work group; by contrast, all forms of incivility from nurses and nurse supervisors did not significantly predict surface acting. This may be due to the fact that, when experiencing incivility from another nurse or a nurse supervisor, nurses are less likely to engage in emotion regulation to fit the expectations of their work role, while nurses may feel it is more important to maintain an organizationsanctioned emotional expression when experiencing incivility from physicians and patients and visitors. Additionally, within the general, physician, and patient and visitor subscales, only the emotion-based well-being outcomes of emotional valence and emotional exhaustion were significantly predicted by the indirect effect model. This finding supports the conceptualization of surface acting as a form of emotion regulation, in which engaging in surface acting as a result of incivility negatively impacts one's emotional valence and increases emotional exhaustion (Grandey, 2000).

Finally, the hypothesized racially-moderated indirect effect model was not supported in either the hypothesis test or the subscale-level exploratory analyses. Similar to the null result when examining Hypothesis 1, this lack of a significant racial moderator could be due to either minority group underreporting or the low base rate of incivility in this sample when compared with past research (Guidroz et al., 2010). A nonsignificant racial difference did emerge when examining the magnitude of the indirect effect; for half of the analyses, the indirect effect for Black nurses was significant while the indirect effect for White nurses was not. While the index of moderated mediation remained 
nonsignificant across outcomes and subscales, indicating that these racial differences in the indirect effect were not significant, these results show there is some influence of race within these relationships such that, in some cases, the influence of incivility on surface acting is stronger for Black nurses than for White nurses. This effect may not have reached significance due to the limited sample size, as well as common method bias. Additionally, the aforementioned survival bias may have impacted this result, such that this sample experienced less incivility as a whole.

\section{Implications}

The present research could have numerous implications for both scholarly research and applied work. First, the impact of incivility from physicians, patients and visitors, and general incivility on emotional well-being outcomes through surface acting provides evidence that surface acting is a negative coping mechanism when experiencing incivility from individuals outside one's work group. Additionally, the trend of significant race moderation in certain indirect effect models for Black nurses indicates that the relationship between incivility and surface acting tends to be stronger for Black nurses. As such, this study provides tentative support for quantitative evidence of racial differences within the emotional labor literature, where it has as of yet only been theoretically and qualitatively examined. Second, significant differences between Black and White nurses on certain incivility subscales indicates that there may exist a racial difference in experiencing incivility. This finding has implications for the aforementioned theory of coercive actions (Tedeschi \& Felson, 1994); individuals may be more likely to be targeted for coercive actions if they belong to a minority racial group. This work could 
inspire future research using different minority populations, whether they be different racial/ethnic minorities, religious minorities, or men, a minority in the nursing population. Additionally, future work could examine the impact of positive coping mechanisms on health outcomes, as opposed to the negative mechanism of surface acting. In applied settings, the present research could inform interventions in nursing. Surface acting proved maladaptive in this sample, especially in terms of emotional wellbeing outcomes. Emotional labor interventions could teach nurses more adaptive behaviors to experiencing incivility, such as deep acting. For example, mindfulness-based strategies could improve one's deep acting skills through self-regulation and cognitive and behavioral flexibility, allowing nurses experiencing incivility to decrease triggered response tendencies, decouple themselves from uncivil events, and take the perspective of and feel empathy for the uncivil party (Glomb, Duffy, Bono, \& Yang, 2011; Brown \& Ryan, 2003). Further, these interventions could target minority populations as high-risk groups, especially with respect to nurse-to-nurse incivility as these experiences differed between racial groups. Finally, Henderson (2001) found that many nurses expressed profound disappointment in the failure of nursing education to address the emotional requirements of the work. The present research could inform nursing education by identifying the disadvantages of engaging in surface acting, as well as positioning incivility as an antecedent to surface acting. Nursing education could, in turn, promote healthier emotional and behavioral responses to incivility. 


\section{Limitations}

As with any research study, the present research does have its limitations. First, the cross-sectional nature of the data does not allow for true causal inferences to be made. It is possible that, within a longitudinal design, the directionality of the proposed mechanisms might be different than hypothesized. For example, one's emotional valence could affect whether or not they perceive an interaction to be uncivil; past research has shown that negative affect is positively related to perceptions of incivility in ambiguous interactions (Sliter, Withrow, \& Jex, 2014). Second, only data from 100 participants could be collected due to reimbursement costs. This relatively small sample size does limit the statistical power that the current study is able to achieve, so the relations I found are likely to be conservative estimates of true relations that could be uncovered within a larger sample. Third, only women were included in this sample, so both gender differences and their intersectionality with racial differences cannot be empirically examined. However, estimates of the proportion of males within the nursing workforce range from nine to 11 percent, so these findings will be generalizable to the majority of the nurse population (Landivar, 2013). A similar limitation exists in the inclusion of only two racial identities: Black and White. However, this racial limitation allows the present research to be the first to look quantitatively at racial differences in surface acting. Fourth and finally, incivility is just one example of many emotional experiences a nurse may have in their day. Emotional work is considered to be "part of the image" of the nursing profession (Mitchell \& Smith, 2003), and this emotional work can range from giving bad news to patients to dealing with difficult family dynamics. Incivility is merely a fraction 
of the emotional work that nurses perform, and thus the present research only scratches the metaphorical surface of emotion work in nursing. 


\section{Conclusion}

To conclude, nurses experience a variety of uncivil interactions at work and may use surface acting as a way to respond to these instances, especially when the incivility is in the form of inappropriate jokes or hostility, or from physicians and patients. Together, these two factors can influence emotional outcomes, increasing emotional exhaustion and negative mood. When compared to White nurses, Black nurses may experience these relationships differently, both in terms of experiencing incivility and responding to it. Black nurses were more likely than White nurses to experience inappropriate identityrelated jokes and hostile behavior in general, and inconsiderate behaviors and free-riding from other nurses specifically. Additionally, in some cases, the influence of incivility on surface acting was stronger for Black nurses than for White nurses, such that Black nurses may be more likely to surface act as a response to incivility than their White counterparts. These findings provide evidence for the emotional impact of experiencing incivility and responding with surface acting and how this relationship may differ between Black and White nurses. 


\section{Tables}

Table 1

Inter-item correlations and reliabilities for all measures $(N=100)$

\begin{tabular}{lccccccc}
\multicolumn{1}{c}{ Outcome } & 1 & 2 & 3 & 4 & 5 & 6 & 7 \\
\hline 1. Incivility & $(.95)$ & & & & & \\
2. Surface acting & $.40^{* *}$ & $(.74)$ & & & & \\
3. Perceptions of health & $-.21^{*}$ & $-.29 * *$ & $(n / a)$ & & & & \\
4. Sleep quality & $-.43^{* *}$ & $-.26^{* *}$ & $.42^{* *}$ & $(.83)$ & & \\
5. Sleep quantity & $-.35^{* * *}$ & -.14 & .19 & $.51^{* *}$ & $(n / a)$ & & \\
6. Emotional valence & $-.47^{* *}$ & $-.30^{* *}$ & $.49 * *$ & $.58^{* *}$ & $.34 * *$ & $(.92)$ & \\
7. Emotional exhaustion & $.49^{* *}$ & $.37^{* *}$ & $-.48^{* *}$ & $-.62^{* *}$ & $-.32^{* *}$ & $-.82^{* *}$ & $(.91)$ \\
\hline
\end{tabular}

Note. Cronbach's alpha reliability values are on the diagonal.

$* p<.05$.

$* * p<.01$. 
Table 2

Group means and standard deviations for all measures

\begin{tabular}{|c|c|c|c|c|c|c|}
\hline \multirow[b]{2}{*}{ Outcome } & \multicolumn{2}{|c|}{$\begin{array}{c}\text { Total } \\
(N=100)\end{array}$} & \multicolumn{2}{|c|}{$\begin{array}{l}\text { White } \\
(n=49)\end{array}$} & \multicolumn{2}{|c|}{$\begin{array}{c}\text { Black } \\
(n=51)\end{array}$} \\
\hline & $M$ & $S D$ & $M$ & $S D$ & $M$ & $S D$ \\
\hline Incivility & 2.09 & 0.63 & 2.01 & 0.51 & 2.18 & 0.73 \\
\hline Surface acting & 3.16 & 0.73 & 3.30 & 0.66 & 3.03 & 0.78 \\
\hline Perceptions of health & 5.27 & 1.22 & 5.22 & 1.21 & 5.31 & 1.26 \\
\hline Sleep quality & 5.02 & 1.79 & 4.95 & 1.64 & 5.09 & 1.94 \\
\hline Sleep quantity & 6.54 & 1.65 & $7.02^{\mathrm{a}}$ & 1.39 & $6.07^{\mathrm{a}}$ & 1.75 \\
\hline Emotional valence & 3.47 & 0.82 & 3.38 & 0.69 & 1.75 & 0.93 \\
\hline Emotional exhaustion & 2.57 & 1.05 & 2.65 & 0.89 & 2.48 & 1.19 \\
\hline
\end{tabular}

Note. $M=$ mean, $S D=$ standard deviation. Group means that share a superscript are significantly different at $p<.05$. 
Table 3

Bootstrap mediation analyses for the effect of incivility on well-being outcomes through surface acting $(N=100)$

Indirect Effect

\begin{tabular}{|c|c|c|c|c|c|c|}
\hline \multirow[b]{2}{*}{ Variable } & \multirow[b]{2}{*}{ Est. MX } & \multirow[b]{2}{*}{ Est. YM } & \multirow[b]{2}{*}{ Direct Effect } & \multirow[b]{2}{*}{ Indirect Effect } & \\
\hline & & & & & LCL & UCL \\
\hline $\begin{array}{l}\text { Perceptions } \\
\text { of health }\end{array}$ & $\begin{array}{c}0.46 * * *(.11) \\
0.39 * * *\end{array}$ & $\begin{array}{c}-0.42 *(.18) \\
-0.25^{*}\end{array}$ & $\begin{array}{l}-0.22(.20) \\
-0.11\end{array}$ & $\begin{array}{c}-0.19 *(.09) \\
-0.01^{*}\end{array}$ & -.39 & -.02 \\
\hline $\begin{array}{l}\text { Sleep } \\
\text { quality }\end{array}$ & & $\begin{array}{c}-0.27(.24) \\
-0.11\end{array}$ & $\begin{array}{c}-1.09 * * *(.28) \\
-0.39 * * *\end{array}$ & $\begin{array}{c}-0.12(.12) \\
-0.04\end{array}$ & -.35 & .11 \\
\hline $\begin{array}{l}\text { Sleep } \\
\text { quantity }\end{array}$ & & $\begin{array}{c}-0.02(.23) \\
-0.01\end{array}$ & $\begin{array}{c}-0.89 * *(.27) \\
-0.34 * *\end{array}$ & $\begin{array}{c}-0.01(.12) \\
-0.01\end{array}$ & -.28 & .23 \\
\hline $\begin{array}{l}\text { Emotional } \\
\text { valence }\end{array}$ & & $\begin{array}{c}-0.16(.11) \\
-0.14\end{array}$ & $\begin{array}{c}-0.53 * * *(.13) \\
-0.41 * * *\end{array}$ & $\begin{array}{c}-0.07(.06) \\
-0.06\end{array}$ & -.19 & .04 \\
\hline $\begin{array}{l}\text { Emotional } \\
\text { exhaustion }\end{array}$ & & $\begin{array}{c}0.30^{*}(.14) \\
0.21^{*}\end{array}$ & $\begin{array}{c}0.68 * * *(.16) \\
0.41 * * *\end{array}$ & $\begin{array}{c}0.14^{*}(.07) \\
0.08^{*}\end{array}$ & .01 & .28 \\
\hline
\end{tabular}

Note: Est. $\mathrm{MX}=$ bootstrapped estimate of the path from incivility to surface acting. Est. $\mathrm{YM}=$ bootstrapped estimate of path from surface acting to well-being outcome. $\mathrm{LCL}=$ lower confidence limit. UCL $=$ upper confidence limit. The estimates of Est. MX are the same across outcomes. Standard errors of the bootstrapped estimates appear in parentheses. Standardized beta estimates appear in italics. One thousand non-bias corrected bootstrap samples.

$* p<.05$.

$* * p<.01$.

$* * * p<.001$. 
Table 4

Bootstrapped conditional indirect effects analyses for the effect of incivility on well-being outcomes through surface acting as a function of race $(N=100)$

\begin{tabular}{|c|c|c|c|c|c|c|c|}
\hline \multirow[b]{2}{*}{ Variable } & \multirow[b]{2}{*}{ Est. MX } & \multirow[b]{2}{*}{ Est. YM } & \multirow[b]{2}{*}{ Direct Effect } & \multirow[b]{2}{*}{ Race } & \multirow{2}{*}{$\begin{array}{l}\text { Indirect } \\
\text { Effect }\end{array}$} & \multicolumn{2}{|c|}{$\begin{array}{l}\text { Indirect } \\
\text { Effect }\end{array}$} \\
\hline & & & & & & LCL & UCL \\
\hline \multirow[t]{2}{*}{$\begin{array}{l}\text { Perceptions of } \\
\text { health }\end{array}$} & $\begin{array}{c}0.34(.39) \\
0.42\end{array}$ & $\begin{array}{c}-0.42 *(.18) \\
-0.25^{*}\end{array}$ & $\begin{array}{c}-0.22(.20) \\
-0.11\end{array}$ & White & $\begin{array}{c}-0.18(.11) \\
-0.09\end{array}$ & -.42 & -.01 \\
\hline & & & & Black & $\begin{array}{c}-0.22(.11) \\
-0.11\end{array}$ & -.47 & -.02 \\
\hline \multirow[t]{2}{*}{ Sleep quality } & & $\begin{array}{c}-0.27(.24) \\
\quad-0.11\end{array}$ & $\begin{array}{c}-1.09 * * *(.28) \\
-0.39 * * *\end{array}$ & White & $\begin{array}{c}-0.12(.12) \\
-0.04\end{array}$ & -.38 & .13 \\
\hline & & & & Black & $\begin{array}{c}-0.14(.13) \\
-0.05\end{array}$ & -.40 & .12 \\
\hline \multirow[t]{2}{*}{ Sleep quantity } & & $\begin{array}{c}-0.02(.23) \\
-0.01\end{array}$ & $\begin{array}{c}-0.89^{* *}(.27) \\
-0.34^{* *}\end{array}$ & White & $\begin{array}{c}-0.01(.12) \\
-0.01\end{array}$ & -.27 & .25 \\
\hline & & & & Black & $\begin{array}{c}-0.01(.14) \\
-0.01\end{array}$ & -.25 & .30 \\
\hline \multirow[t]{2}{*}{$\begin{array}{l}\text { Emotional } \\
\text { valence }\end{array}$} & & $\begin{array}{c}-0.16(.11) \\
-0.14\end{array}$ & $\begin{array}{c}-0.53 * * *(.13) \\
-0.41 * * *\end{array}$ & White & $\begin{array}{c}-0.07(.07) \\
-0.05\end{array}$ & -.21 & .05 \\
\hline & & & & Black & $\begin{array}{c}-0.08(.07) \\
-0.06\end{array}$ & -.24 & .05 \\
\hline \multirow[t]{2}{*}{$\begin{array}{l}\text { Emotional } \\
\text { exhaustion }\end{array}$} & & $\begin{array}{c}0.30^{*}(.14) \\
0.21^{*}\end{array}$ & $\begin{array}{c}0.68 * * *(.16) \\
0.41 * * *\end{array}$ & White & $\begin{array}{c}0.13(.09) \\
0.08\end{array}$ & -.01 & .31 \\
\hline & & & & Black & $\begin{array}{c}0.16(.08) \\
0.10\end{array}$ & .01 & .34 \\
\hline
\end{tabular}

Note: Est. $\mathrm{MX}=$ bootstrapped estimate of the path from incivility to surface acting. Est. $\mathrm{YM}=$ bootstrapped estimate of path from surface acting to well-being outcome. $\mathrm{LCL}=$ lower confidence limit. UCL $=$ upper confidence limit. The estimates of Est. MX are the same across outcomes. Standard errors of the bootstrapped estimates appear in parentheses. Standardized beta estimates appear in italics. One thousand non-bias corrected bootstrap samples.

$* p<.05$.

$* * p<.01$.

$* * * p<.001$. 
Table 5

Independent samples t-tests on NIS subscales by race

\begin{tabular}{|c|c|c|c|c|c|c|}
\hline \multirow[b]{2}{*}{ Subscale } & \multicolumn{2}{|c|}{$\begin{array}{l}\text { White } \\
(N=49)\end{array}$} & \multicolumn{2}{|c|}{$\begin{array}{c}\text { Black } \\
(N=51)\end{array}$} & \multirow[b]{2}{*}{$d f$} & \multirow[b]{2}{*}{$t$} \\
\hline & $M$ & $S D$ & $M$ & $S D$ & & \\
\hline \multicolumn{7}{|l|}{ General Incivility } \\
\hline Inappropriate jokes & 1.48 & 0.56 & 1.95 & 1.06 & 76.32 & $2.76 * *$ \\
\hline Hostility/rudeness & 2.28 & 0.67 & 2.74 & 0.97 & 89.09 & $2.76^{* *}$ \\
\hline \multicolumn{7}{|l|}{ Nurse Incivility } \\
\hline Inconsiderate behavior & 1.31 & 0.45 & 1.66 & 0.80 & 79.66 & $2.68 * *$ \\
\hline Gossip/ rumors & 2.80 & 1.18 & 3.21 & 1.40 & 98 & 1.61 \\
\hline Free-riding & 1.67 & 0.80 & 2.44 & 1.21 & 87.16 & $3.81 * * *$ \\
\hline Supervisor Incivility & 1.42 & 0.76 & 1.55 & 0.77 & 98 & 0.85 \\
\hline Physician Incivility & 2.13 & 0.87 & 2.02 & 0.99 & 98 & 0.57 \\
\hline Patient/Visitor Incivility & 2.46 & 0.89 & 2.18 & 1.01 & 98 & 1.46 \\
\hline
\end{tabular}

Note. $M=$ mean, $S D=$ standard deviation. Comparisons with 98 degrees of freedom were not adjusted for variance inequality.

$* * p<.01$. $* * * p<.001$. 
Table 6

NIS subscale-level correlations with outcome variables $(N=100)$

\begin{tabular}{|c|c|c|c|c|c|c|}
\hline Subscale & $\begin{array}{l}\text { Surface } \\
\text { acting }\end{array}$ & $\begin{array}{l}\text { Perceptions } \\
\text { of health }\end{array}$ & $\begin{array}{l}\text { Sleep } \\
\text { quality }\end{array}$ & $\begin{array}{c}\text { Sleep } \\
\text { quantity }\end{array}$ & $\begin{array}{l}\text { Emotional } \\
\text { valence }\end{array}$ & $\begin{array}{l}\text { Emotional } \\
\text { exhaustion }\end{array}$ \\
\hline \multicolumn{7}{|l|}{ General incivility } \\
\hline $\begin{array}{l}\text { Inappropriate } \\
\text { jokes }\end{array}$ & $.24 *$ & -.14 & -.19 & -.17 & $-.27 * *$ & $.33 * *$ \\
\hline Hostility/rudeness & $.27 * *$ & $-.20 *$ & $-.29 *$ & $-.28 * *$ & $-.31 * *$ & $.30 * *$ \\
\hline \multicolumn{7}{|l|}{ Nurse incivility } \\
\hline $\begin{array}{l}\text { Inconsiderate } \\
\text { behavior }\end{array}$ & .18 & -.08 & -.14 & $-.22 *$ & $-.23 *$ & $.21^{*}$ \\
\hline Gossip/rumors & .14 & -.11 & $-.27 * *$ & $-.24 *$ & $-.40 * *$ & $.35 * *$ \\
\hline Free-riding & .13 & -.01 & -.11 & -.17 & -.11 & .16 \\
\hline Supervisor incivility & .12 & -.13 & $-.29 * *$ & $-.26 * *$ & $-.25 *$ & $.33 * *$ \\
\hline Physician incivility & $.42 * *$ & $-.23 *$ & $-.43 * *$ & $-.35 * *$ & $-.46 * *$ & $.44 * *$ \\
\hline $\begin{array}{l}\text { Patient/visitor } \\
\text { incivility }\end{array}$ & $.41 * *$ & -.15 & $-.37 * *$ & -.17 & $-.35^{* *}$ & $.38^{* *}$ \\
\hline
\end{tabular}

$* p<.05$.

$* * p<.01$ 


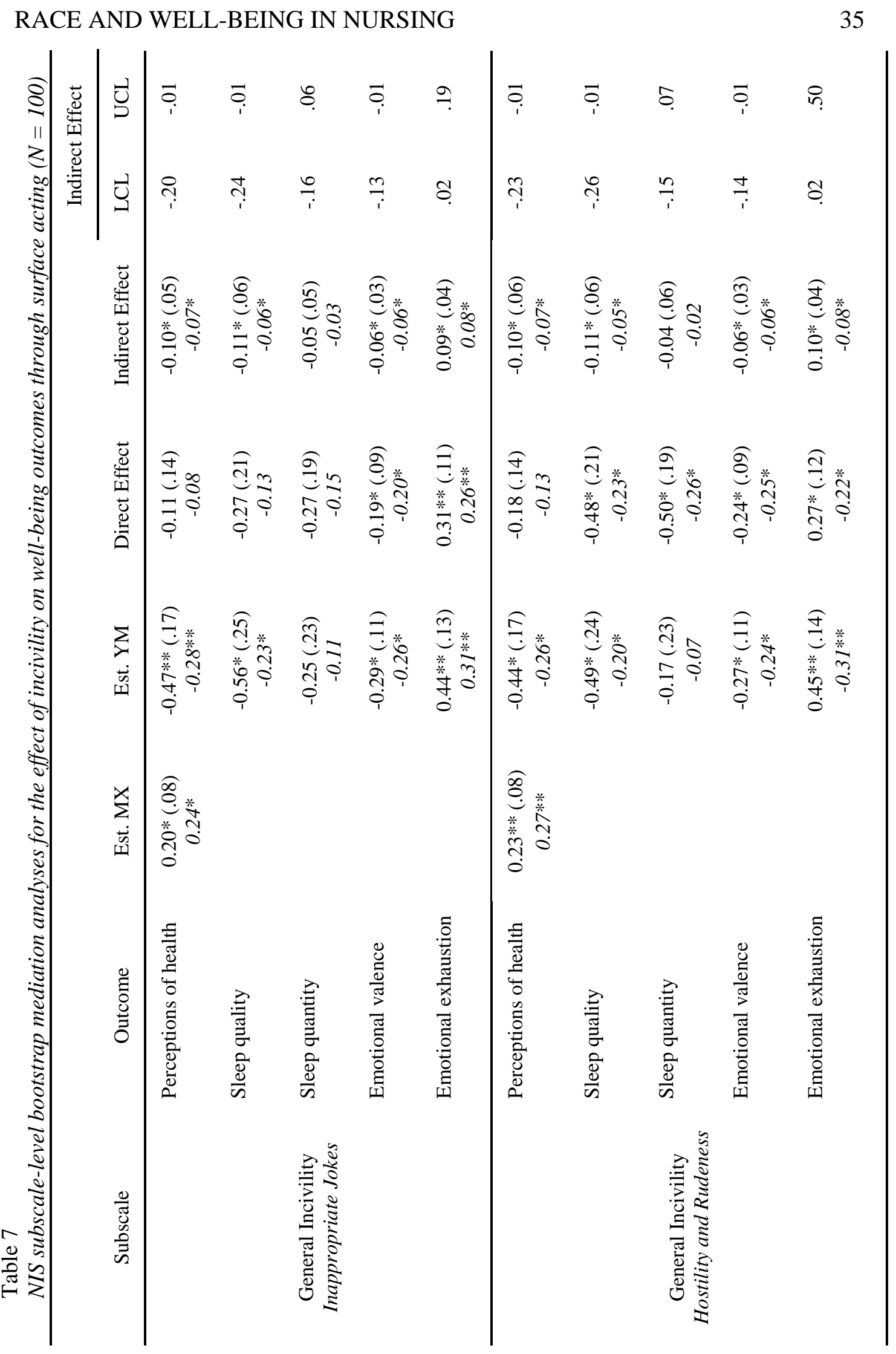


RACE AND WELL-BEING IN NURSING

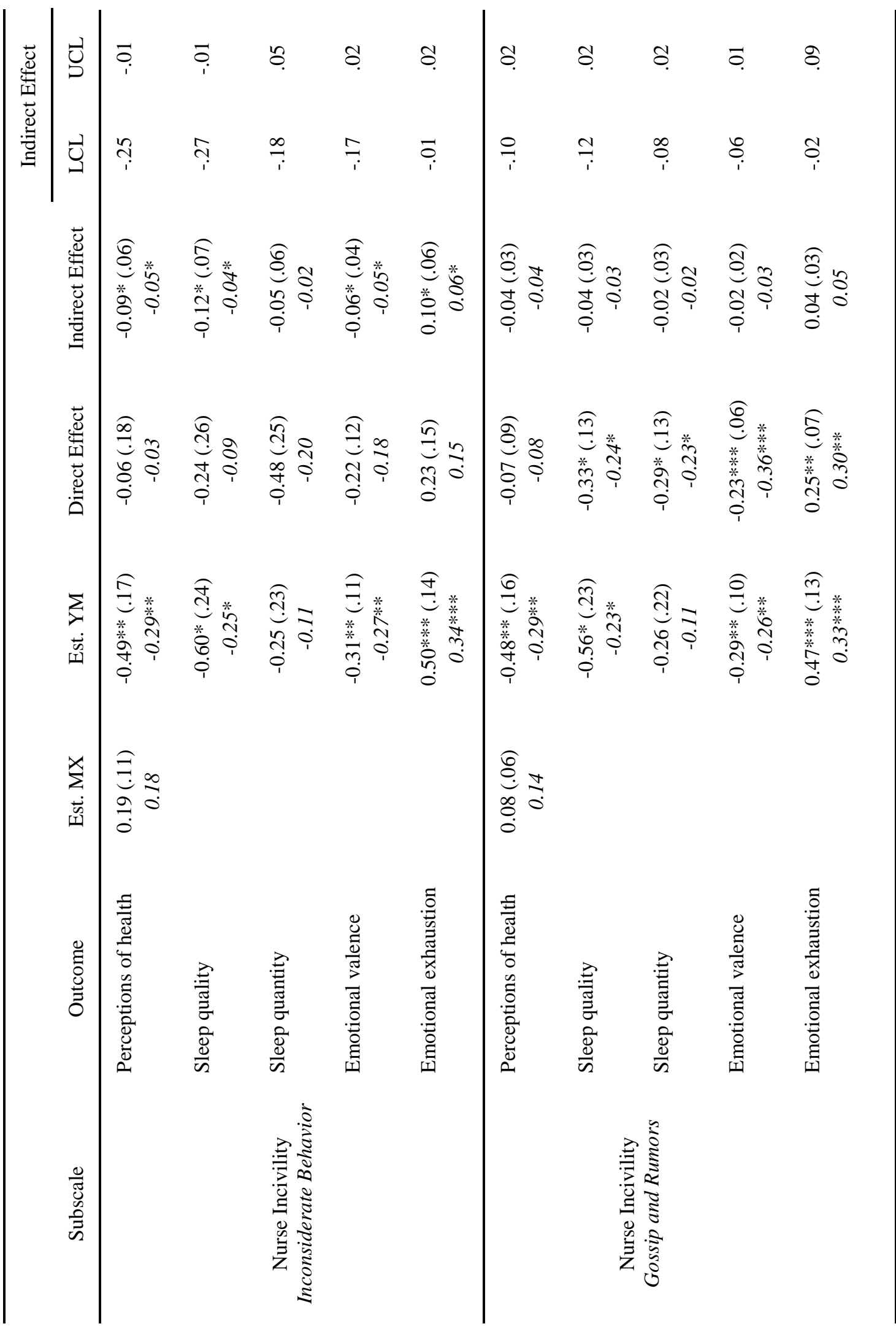




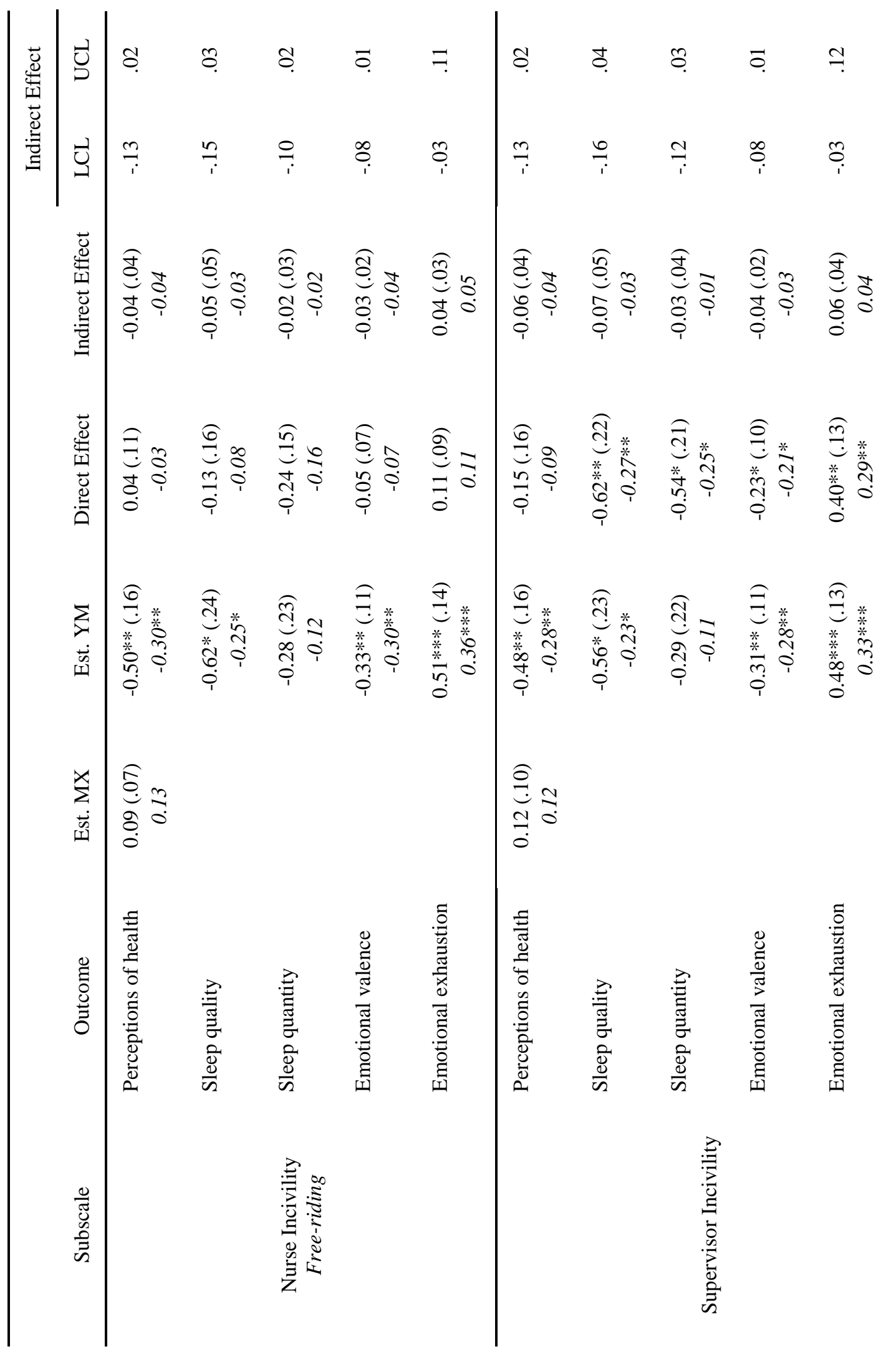


RACE AND WELL-BEING IN NURSING

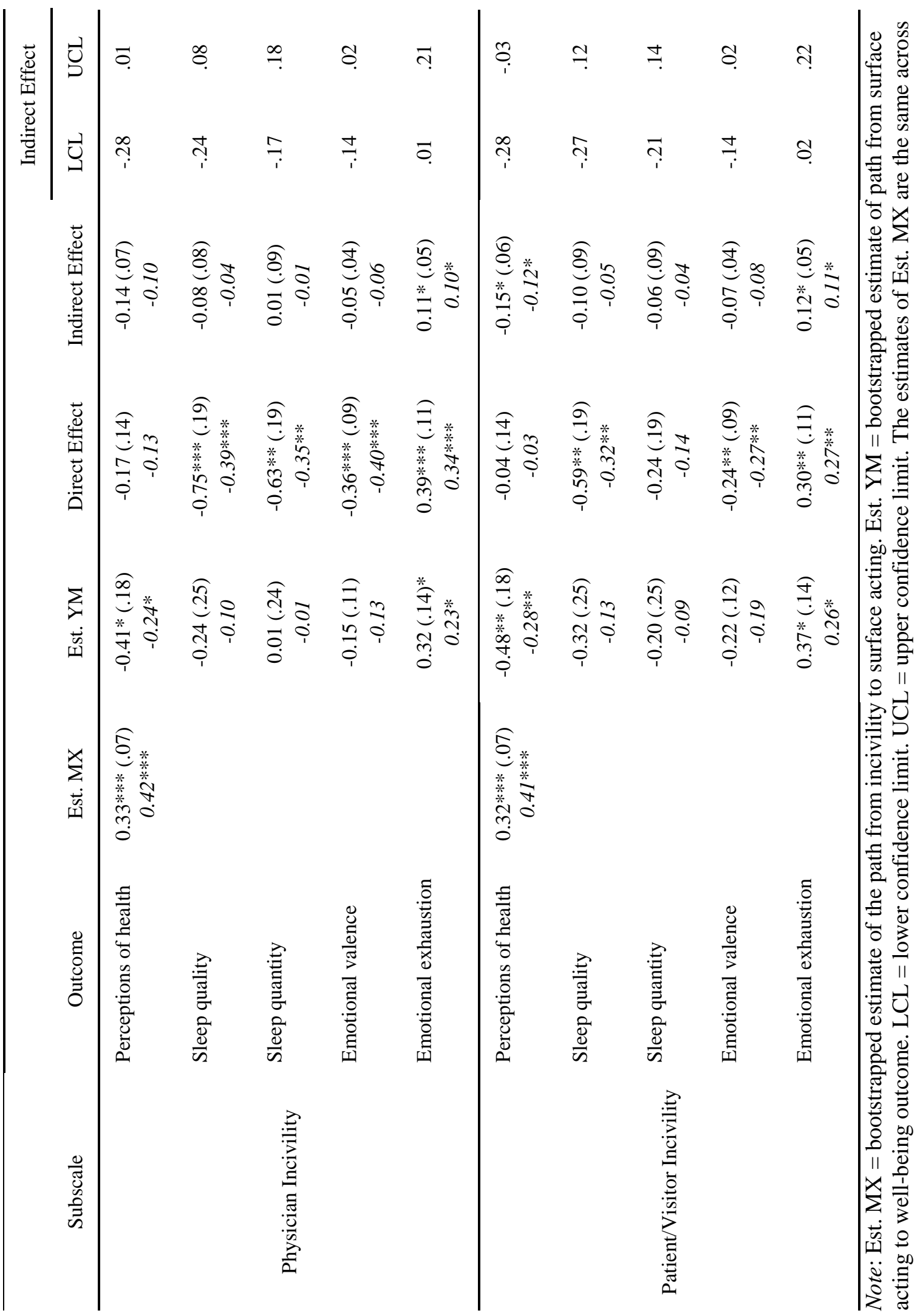




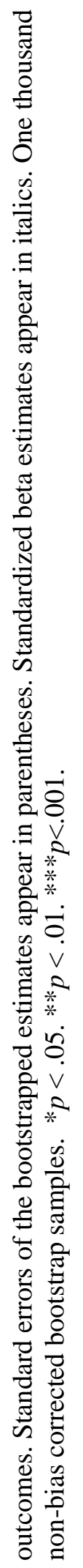




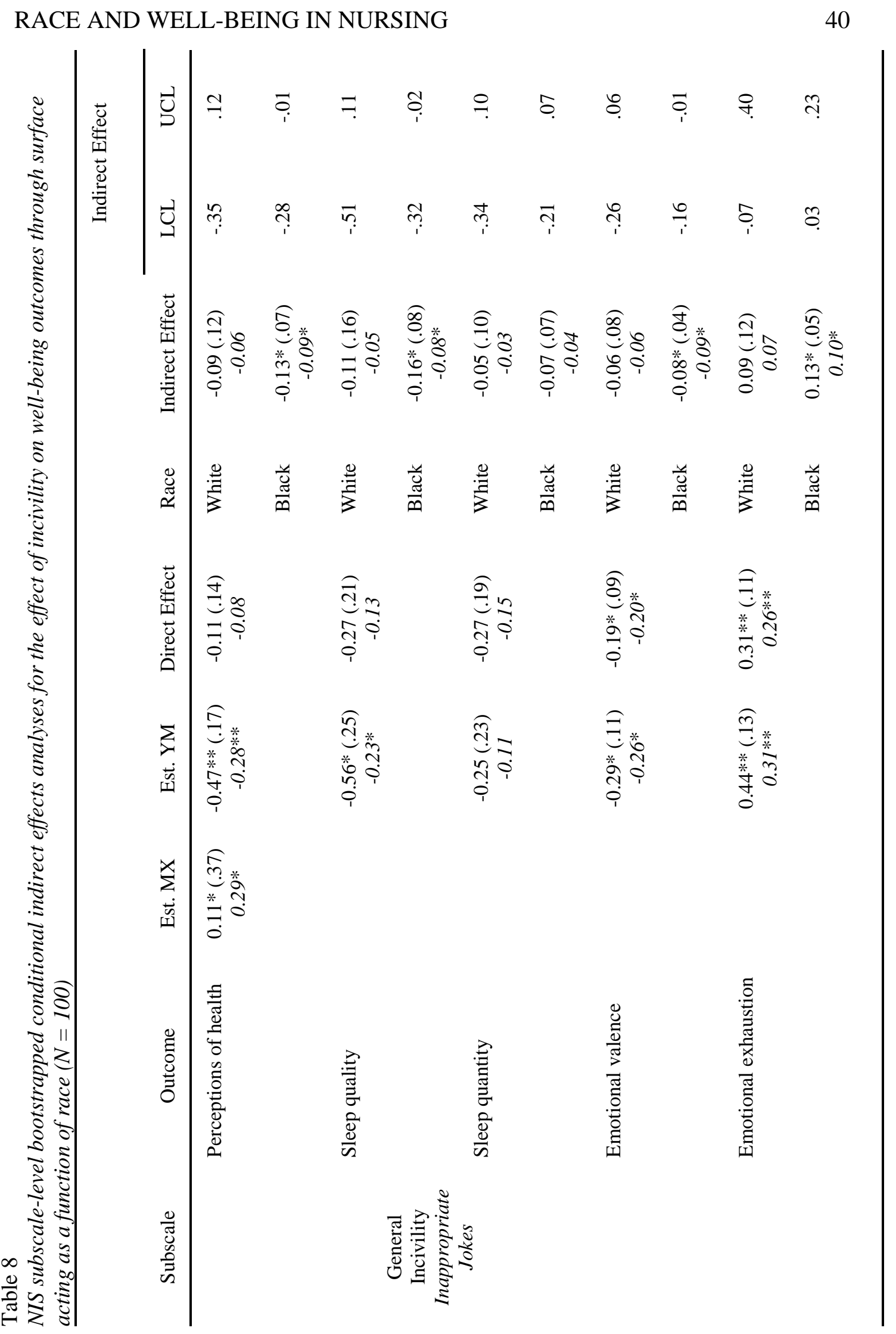


RACE AND WELL-BEING IN NURSING

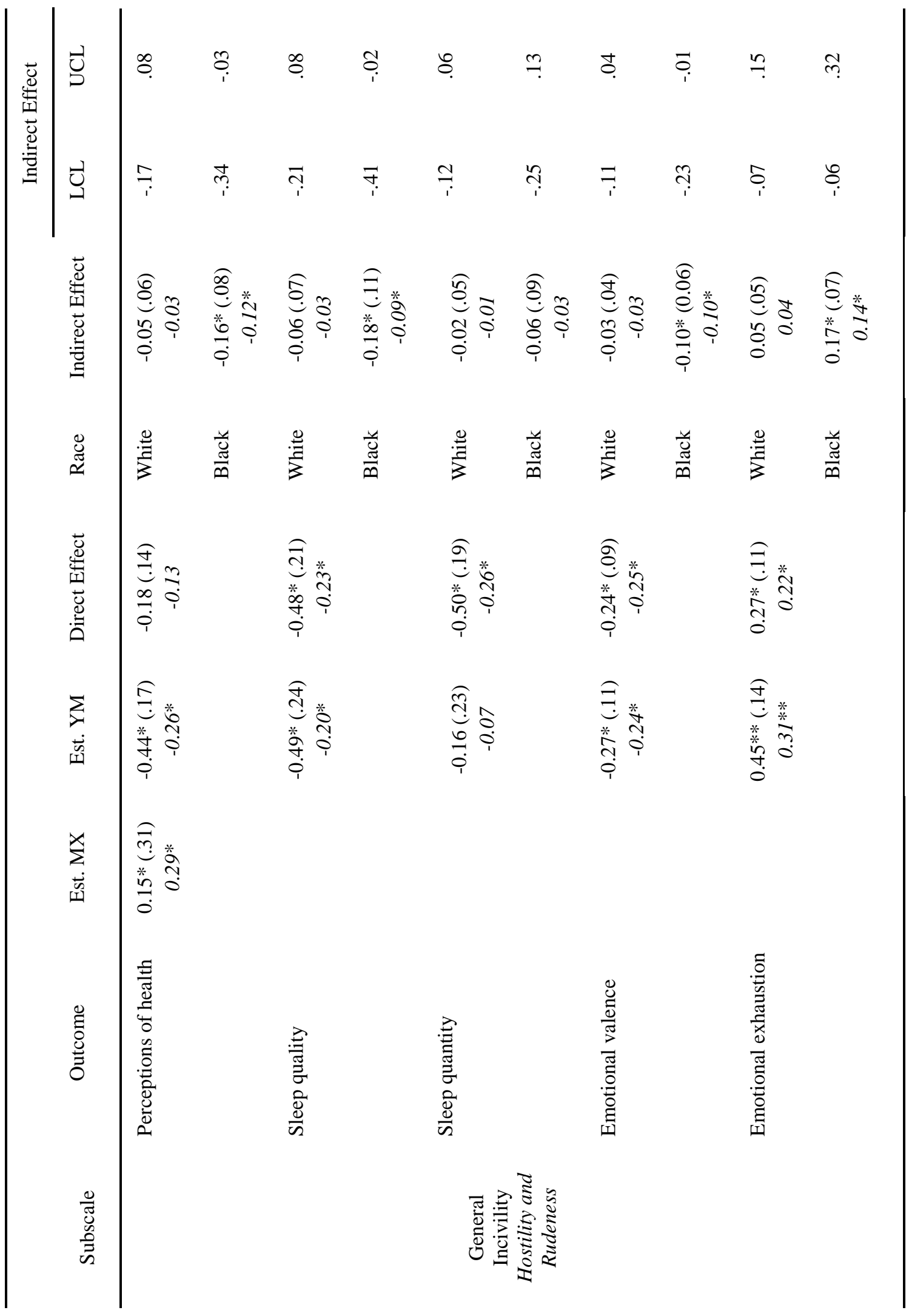


RACE AND WELL-BEING IN NURSING

\begin{tabular}{|c|c|c|c|c|c|c|c|c|c|c|}
\hline 己ે & \pm & $\delta_{i}$ & $\stackrel{\simeq}{\simeq}$ & $\tilde{o}_{i}$ & gे. & $=$ & oे. & $\overline{0}$ & ড় & $\ddot{n}$ \\
\hline త్త & $\stackrel{\overbrace{}}{\dddot{y}}$ & भे. & $\stackrel{n}{n}$ & $\underset{i}{F}$ & 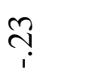 & 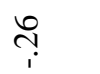 & $\stackrel{7}{7}$ & 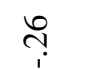 & $\underset{i}{ \pm}$ & 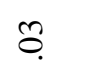 \\
\hline 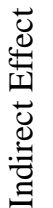 & 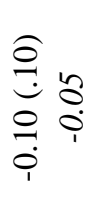 & 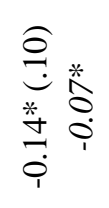 & 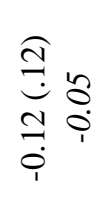 & 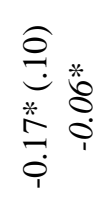 & 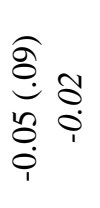 & 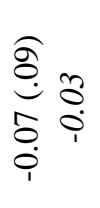 & 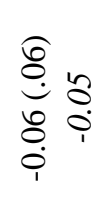 & 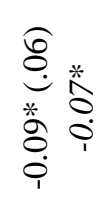 & $\begin{array}{l}\underset{\hat{d}}{\dot{0}} \stackrel{0}{\circ} \\
\stackrel{0}{0}\end{array}$ & $\begin{array}{l}\hat{\sigma} \\
\begin{array}{l}* \\
0\end{array} \\
\frac{*}{0} \\
0\end{array}$ \\
\hline $\begin{array}{l}\mathscr{\mathscr { U }} \\
\widetilde{\check{\varkappa}}\end{array}$ & $\frac{\mathscr{g}}{3}$ & $\begin{array}{l}\frac{\ddot{0}}{\tilde{m}} \\
\frac{\pi}{m}\end{array}$ & 莺 & $\begin{array}{l}\frac{\ddot{y}}{\tilde{m}} \\
\frac{\pi}{m}\end{array}$ & 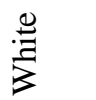 & $\begin{array}{l}\frac{\ddot{0}}{\underline{0}} \\
\frac{\pi}{m}\end{array}$ & $\frac{\mathscr{n}}{\frac{\mathscr{n}}{3}}$ & $\begin{array}{l}\frac{\ddot{0}}{\tilde{m}} \\
\frac{\pi}{n}\end{array}$ & 营 & $\begin{array}{l}\frac{\ddot{0}}{\tilde{m}} \\
\frac{\pi}{n}\end{array}$ \\
\hline 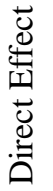 & 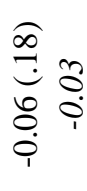 & & 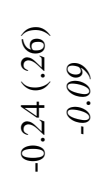 & & 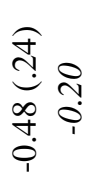 & & 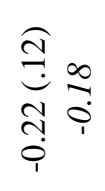 & & 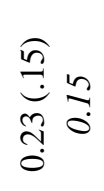 & \\
\hline 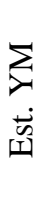 & 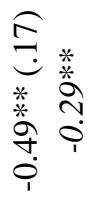 & & 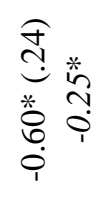 & & 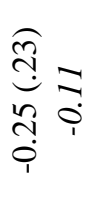 & & 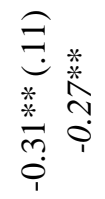 & & 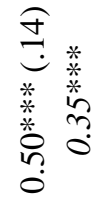 & \\
\hline 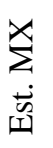 & 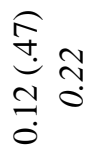 & & & & & & & & & \\
\hline 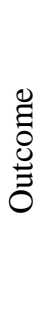 & 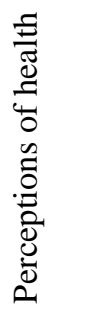 & & 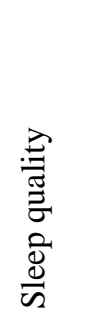 & & 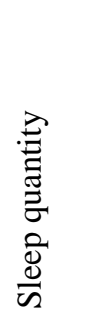 & & 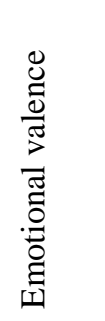 & & 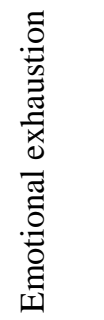 & \\
\hline 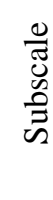 & & & & & & 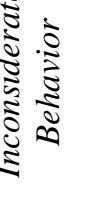 & & & & \\
\hline
\end{tabular}


RACE AND WELL-BEING IN NURSING

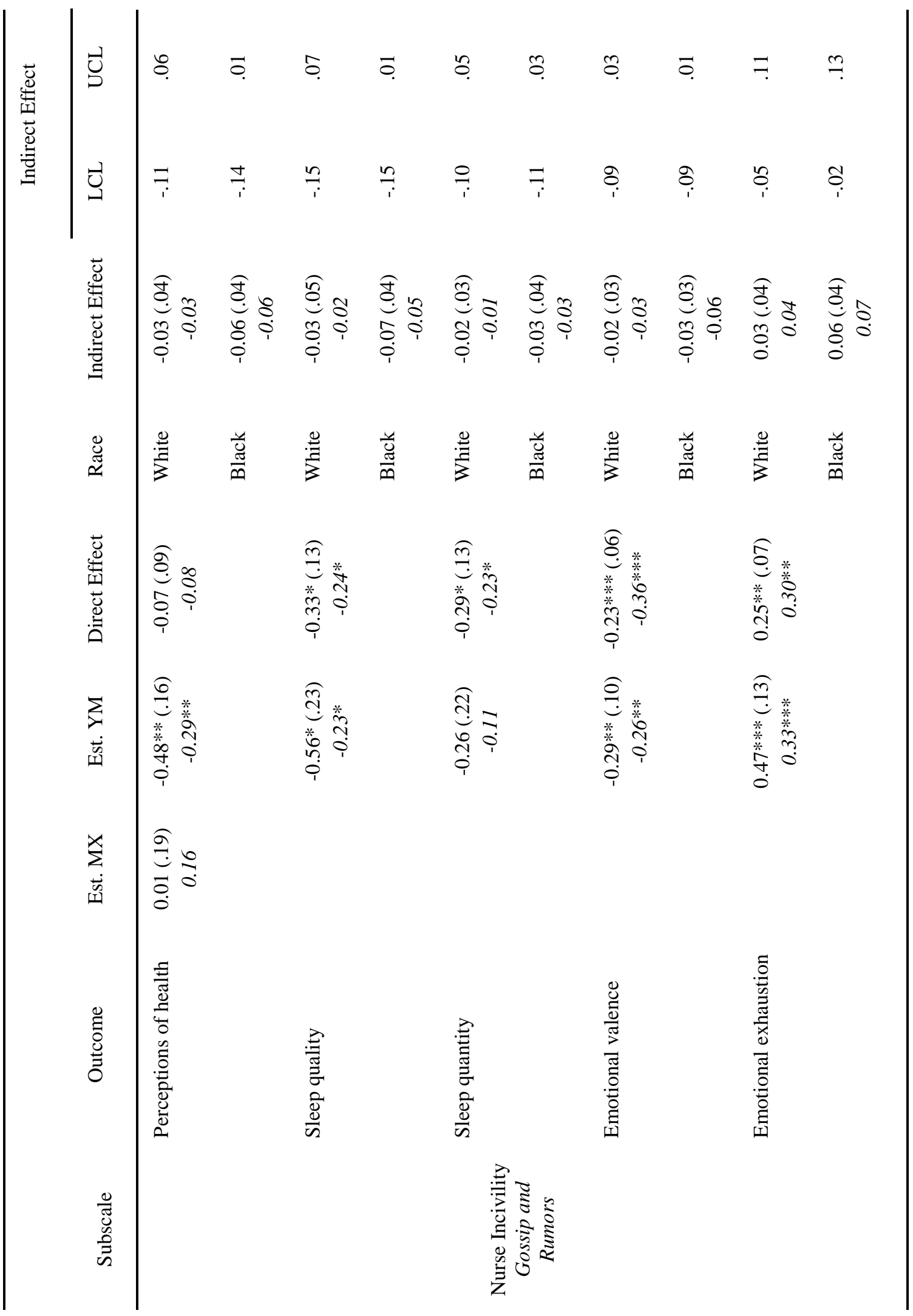


RACE AND WELL-BEING IN NURSING

\begin{tabular}{|c|c|c|c|c|c|c|c|c|c|c|}
\hline 己ِ & 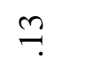 & $\tilde{\sigma}_{i}$ & 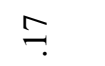 & $\delta_{i}$ & $\stackrel{?}{\circ}$ & $\ddot{c}$ & ô. & $\overline{0}$ & 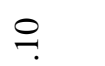 & $\vec{\Upsilon}$ \\
\hline$\vec{U}$ & $\underset{i}{7}$ & $\stackrel{\overbrace{}}{i}$ & $\underset{i}{ \pm}$ & $\stackrel{\overbrace{}}{i}$ & $\hat{s}_{i}$ & 7 & $\hat{s}_{i}$ & $\stackrel{n}{i}$ & $\stackrel{9}{i}$ & 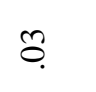 \\
\hline 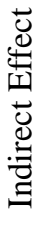 & $\begin{array}{l}\stackrel{0}{8} \\
\stackrel{\oplus}{0} \\
\stackrel{0}{\circ}\end{array}$ & 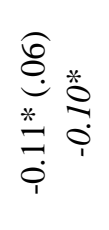 & $\begin{array}{l}\hat{s} \\
\stackrel{0}{0} \\
0 \\
0\end{array}$ & 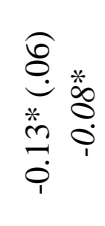 & 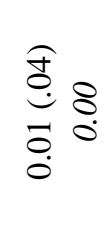 & 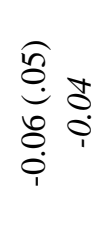 & $\begin{array}{l}\frac{1}{0} \\
\stackrel{0}{0} \\
0 \\
0\end{array}$ & 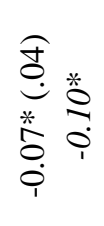 & $\begin{array}{l}\stackrel{8}{8} \\
\stackrel{0}{8} \\
\stackrel{0}{0} \\
i\end{array}$ & 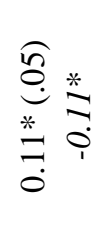 \\
\hline $\begin{array}{l}\mathscr{\mathscr { E }} \\
\text { ฯ }\end{array}$ & $\stackrel{\stackrel{9}{*}}{\sum_{3}}$ & 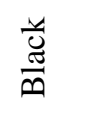 & 受 & $\begin{array}{l}\frac{u}{\ddot{g}} \\
\frac{\pi}{m}\end{array}$ & $\stackrel{\frac{\mathscr{V}}{3}}{3}$ & $\begin{array}{l}\frac{u}{\tilde{g}} \\
\frac{\vec{g}}{m}\end{array}$ & 营 & $\frac{\ddot{u}}{\frac{\ddot{m}}{m}}$ & 受 & $\begin{array}{l}\frac{\ddot{y}}{\tilde{J}} \\
\frac{\pi}{\oplus}\end{array}$ \\
\hline 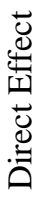 & 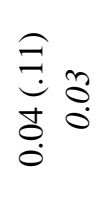 & & 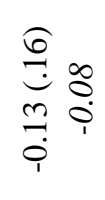 & & 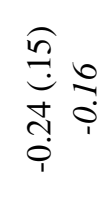 & & 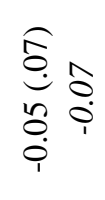 & & $\underset{0}{\stackrel{\sigma}{G}}=$ & \\
\hline $\begin{array}{l}\sum_{i} \\
\vec{\Delta} \\
\overrightarrow{4}\end{array}$ & 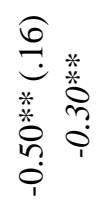 & & 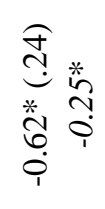 & & 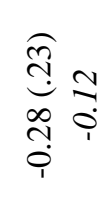 & & 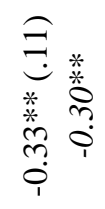 & & 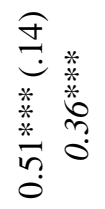 & \\
\hline 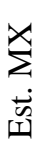 & 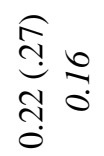 & & & & & & & & & \\
\hline 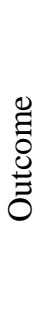 & 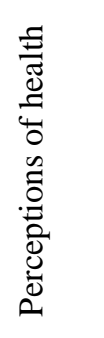 & & 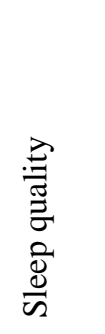 & & 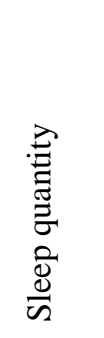 & & 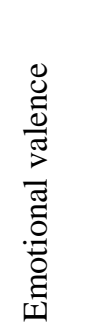 & & 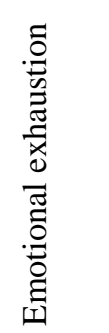 & \\
\hline $\begin{array}{l}0 \\
\bar{b} \\
\bar{n}\end{array}$ & & & & & & 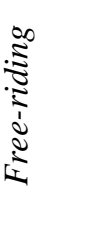 & & & & \\
\hline
\end{tabular}


RACE AND WELL-BEING IN NURSING

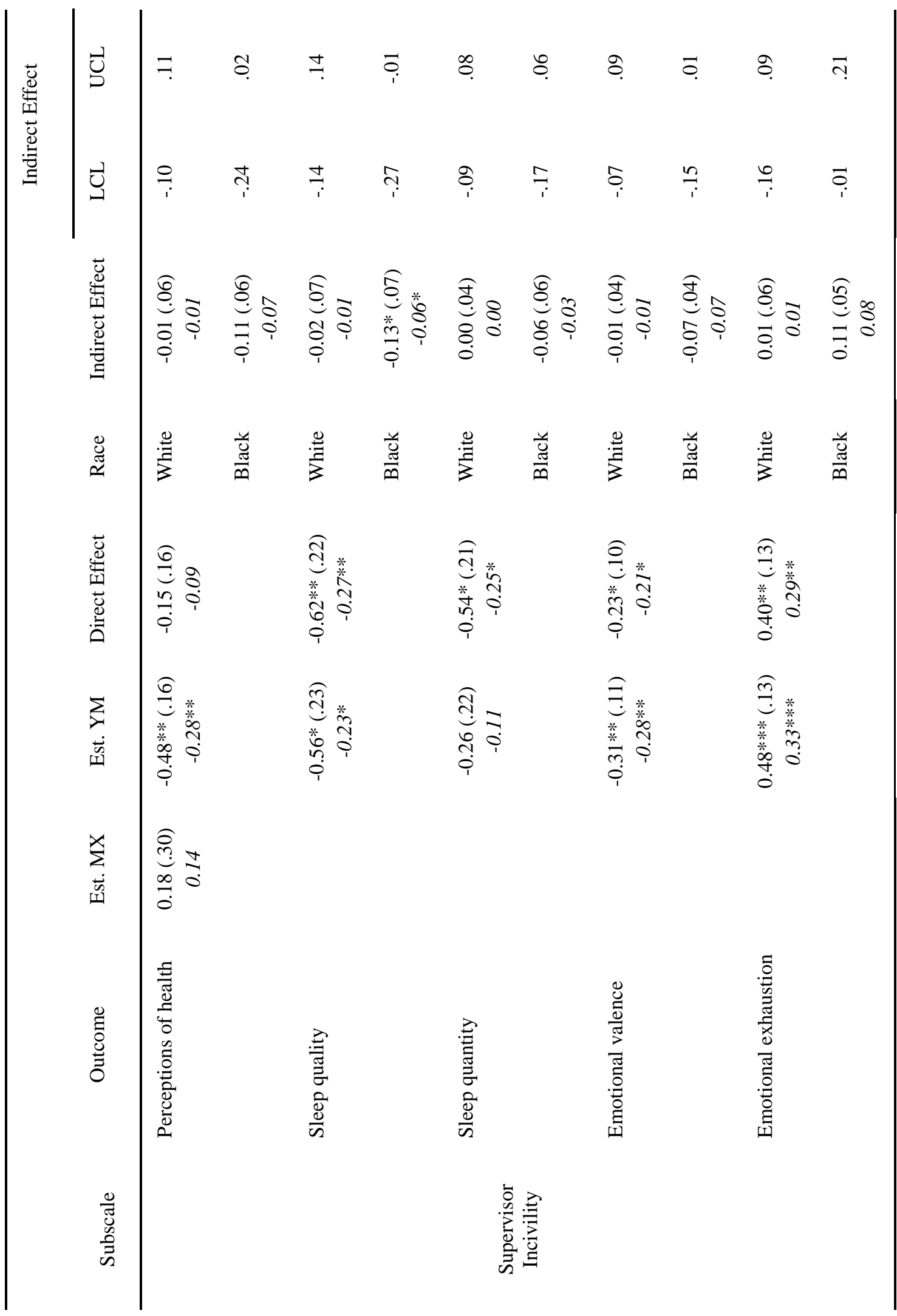


RACE AND WELL-BEING IN NURSING

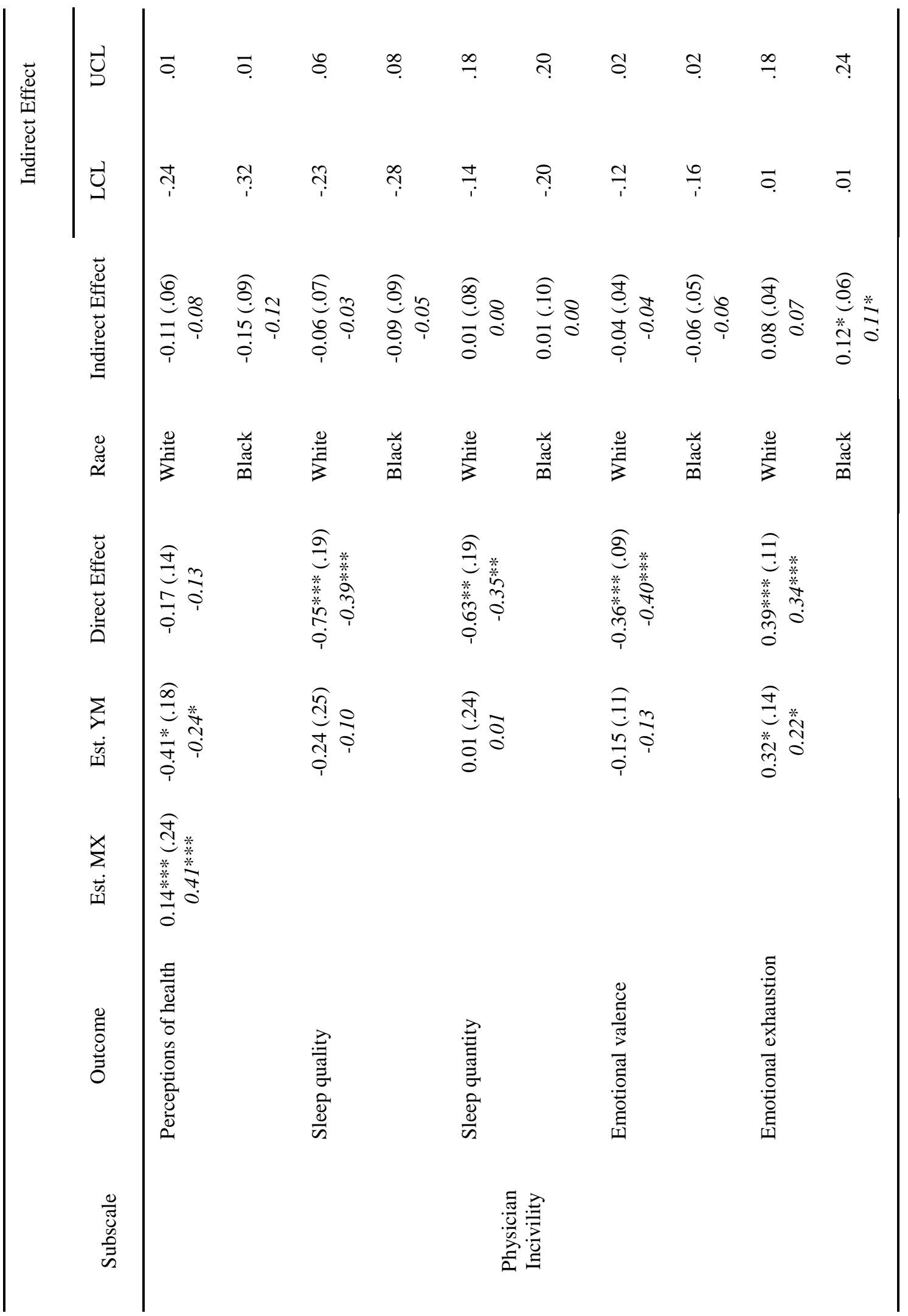


RACE AND WELL-BEING IN NURSING

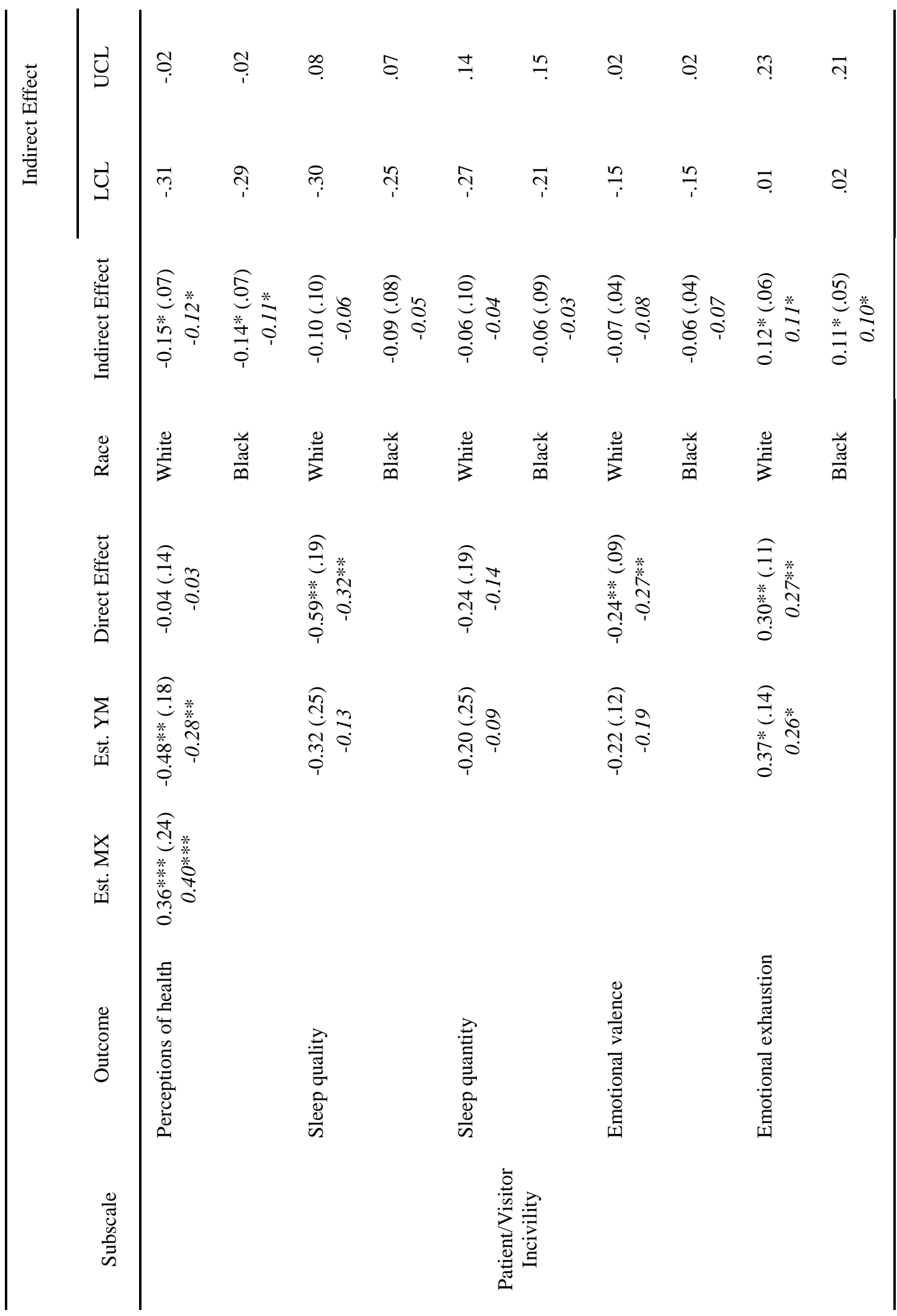




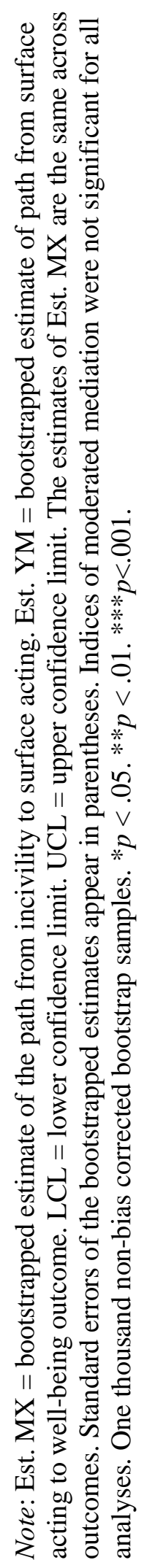




\section{Figures}

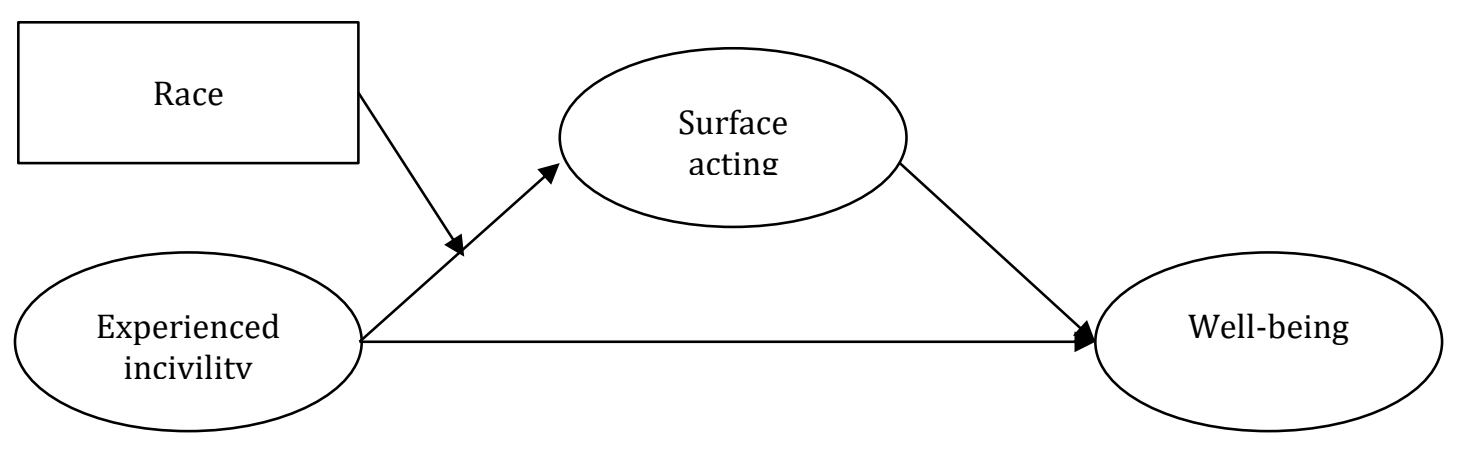

Figure 1. Theoretical model. 


\section{References}

Abraham, R. (1998). Emotional dissonance in organizations: antecedents, consequences, and moderators. Genetic, Social, and General Psychology Monographs, 124, 229-246. Retrieved from: https://www.ncbi.nlm.nih.gov/pubmed/9597747

Adams, G. A., \& Webster, J. R. (2013). Emotional regulation as a mediator between interpersonal mistreatment and distress. European Journal of Work and Organizational Psychology, 22, 697-710.

https://doi.org/10.1080/1359432X.2012.698057

American Association of Colleges of Nursing. (2015). Enhancing diversity in the nursing workforce fact sheet. Washington, DC. Retrieved from http://www.aacnnursing.org/Portals/42/News/Factsheets/Enhancing-DiversityFactsheet-2017.pdf

Andersson, L. M., \& Pearson, C. M. (1999). Tit for tat? The spiraling effect of incivility in the workplace. Academy of Management Review, 24, 452-471. https://doi.org/10.5465/AMR.1999.2202131

Ashforth, B. E., \& Humphrey, R. H. (1993). Emotional labor in service roles: The influence of identity. Academy of Management Review, 18, 88-115. https://doi.org/10.5465/AMR.1993.3997508

Baumeister, R. F., Bratslavsky, E., Muraven, M., \& Tice, D. M. (1998). Ego depletion: Is the active self a limited resource? Journal of Personality and Social Psychology, 74, 1252-1265. Retrieved from: 
https://faculty.washington.edu/jdb/345/345\%20Articles/Baumeister\%20et\%20al. $\% 20(1998) \cdot p d f$

Bayne, A. M. (2015). Relationships between incivility and physical health: The mediating effect of sleep and moderating effects of hostile attribution bias and rumination in a sample of nurses. (Unpublished master's thesis).Bowling Green State University, Bowling Green, O.H. Retrieved from https://etd.ohiolink.edu/!etd.send_file?accession=bgsu1447257217\&disposition=i nline

Best, R. G., Downey, R. G., \& Jones, R. G. (1997, April). Incumbent perceptions of emotional work requirements. Paper presented at the 12th annual conference of the Society for Industrial and Organizational Psychology, St. Louis, Missouri.

Björkqvist, K., Österman, K., \& Hjelt-Bäck, M. (1994). Aggression among university employees. Aggressive Behavior, 20, 173-184. https://doi.org/10.1002/10982337(1994)20:3<173::AID-AB2480200304>3.0.CO;2-D

Blau, G., \& Andersson, L. M. (2005). Testing a measure of instigated workplace incivility. Journal of Occupational and Organizational Psychology, 78, 595-614. https://doi.org/10.1348/096317905X26822

Brotheridge, C. M., \& Grandey, A. A. (2002). Emotional labor and burnout: Comparing two perspectives of "people work." Journal of Vocational Behavior, 60, 17-39. https://doi.org/10.1006/jvbe.2001.1815 
Brotheridge, C. M., \& Lee, R. (2003). Development and validation of the Emotional Labour Scale. Journal of Occupational and Organizational Psychology, 76, 365379. http://dx.doi.org/10.1348/096317903769647229

Brown, K. W., \& Ryan, R. M. (2003). The benefits of being present: Mindfulness and its role in psychological well-being. Journal of Personality and Social Psychology, 84, 822-848. doi: 10.1037/0022-3514.84.4.822

Buysse, D. J., Reynolds, C. F., Monk, T. H., Berman, S. R., \& Kupfer, D. J. (1989). The Pittsburgh Sleep Quality Index: A new instrument for psychiatric practice and research. Psychiatry Research, 28, 193-213. Retrieved from: https://www.ncbi.nlm.nih.gov/pubmed/2748771

Cortina, L. M. (2008). Unseen injustice: Incivility as modern discrimination in organizations. Academy of Management Review, 33, 55-75. https://doi.org/10.5465/AMR.2008.27745097

Cortina, L. M., Kabat-Farr, D., Leskinen, E. A., Huerta, M., \& Magley, V. J. (2013). Selective incivility as modern discrimination in organizations: Evidence and impact. Journal of Management, 39, 1579-1605. https://doi.org/10.1177/0149206311418835

Cortina, L. M., Magley, V. J., Williams, J. H., \& Langhout, R. D. (2001). Incivility in the workplace: Incidence and impact. Journal of Occupational Health Psychology, 6(1), 64-80. https://doi.org/10.1037//1076-8998.6.1.64

Crosby, F. (1982). Relative deprivation and working women. New York, N.Y.: Oxford University Press. 
Crosby, F., Pufall, A., Snyder, R. C., O'Connell, M., \& Whalen, P. (1989). The denial of personal disadvantage among you, me, and all the other ostriches. In M. Crawford \& M. Gentry (Eds.), Gender and thought (pp. 79-99). New York, N.Y.: SpringerVerlag.

Dahling, J. J., \& Perez, L. A. (2010). Older worker, different actor? Linking age and emotional labor strategies. Personality and Individual Differences, 48, 574-578. https://doi.org/10.1016/j.paid.2009.12.009

de Jonge, J., Le Blanc, P. M., Peeters, M. C. W., \& Noordam, H. (2008). Emotional job demands and the role of matching job resources: A cross-sectional survey study among health care workers. International Journal of Nursing Studies, 45, 14601469. https://doi.org/10.1016/j.ijnurstu.2007.11.002

Demsky, C. A., Fritz, C., Hammer, L. B., \& Black, A. E. (2018). Workplace incivility and employee sleep: The role of rumination and recovery experiences. Journal of Occupational Health Psychology. Advanced online publication. http://dx.doi.org/10.1037/ocp0000116

Dollard, J., Doob, L. W., Miller, N. E., Mowrer, O. H., \& Sears, R. R. (1939). Frustration and aggression. New Haven, CT: Yale University Press. Ekman, P., \& Friesen, W. V. (1969). Nonverbal leakage and clues to deception. Psychiatry, 32(1), 88-106. Retrieved from: https://www.paulekman.com/wpcontent/uploads/2013/07/Nonverbal-Leakage-And-Clues-To-Deception.pdf

Etienne, E. (2014). Exploring workplace bullying in nursing. Workplace Health \& Safety, 62(1), 6-11. https://doi.org/10.1177/216507991406200102 
Evans, L. (2012). Facing racism at 30,000 feet: African American pilots, flight attendants, and emotional labor (Unpublished doctoral dissertation). Texas A\&M University, College Station, T.X. Retrieved from http://oaktrust.library.tamu.edu/handle/1969.1/ETD-TAMU-2012-05-11127

Felblinger, D. M. (2008). Incivility and bullying in the workplace and nurses' shame responses. Journal of Obstetric, Gynecologic, and Neonatal Nursing, 37, 234241. https://doi.org/10.1111/j.1552-6909.2008.00227.x

Felblinger, D. M. (2009). Bullying, incivility, and disruptive behaviors in the healthcare setting: Identification, impact, and intervention. Frontiers of Health Services Management, 25(4), 13-23. Retrieved from: https://www.ncbi.nlm.nih.gov/pubmed/19603687

Gaffney, D. A., DeMarco, R. F., Hofmeyer, A., Vessey, J. A., \& Budin, W. C. (2012). Making things right: Nurses' experiences with workplace bullying-A grounded theory. Nursing Research and Practice (2012), 1-10. https://doi.org/10.1155/2012/243210

Giumetti, G. W., Hatfield, A. L., Scisco, J. L., Schroeder, A. N., Muth, E. R., \& Kowalski, R. M. (2013). What a rude e-mail! Examining the differential effects of incivility versus support on mood, energy, engagement, and performance in an online context. Journal of Occupational Health Psychology, 18, 297-309. https://doi.org/10.1037/a0032851 
Glomb, T. M., Duffy, M. K., Bono, J.E., \& Yang, T. (2011). Mindfulness at work. Research in Personnel and Human Resources Management, 30, 115-157. doi: 10.1108/S0742-7301(2011)0000030005

Grandey, A. A. (2000). Emotional regulation in the workplace: A new way to conceptualize emotional labor. Journal of Occupational Health Psychology, 5, 95-110. https://doi.org/10.1037//1076-8998.5.1.95

Gross, J. J., \& Levenson, R. W. (1997). Hiding feelings: The acute effects of inhibiting negative and positive emotion. Journal of Abnormal Psychology, 106, 95-103. Retrieved from https://www.ncbi.nlm.nih.gov/pubmed/9103721

Grove, S. J., \& Fisk, R. P. (1989). Impression management in services marketing: A dramaturgical perspective. In R. A. Giacalone \& P. Rosenfeld (Eds.), Impression management in the organization (pp. 427-438). Hillsdale, NJ: Erlbaum.

Grusec, J. E., \& Kuczynski, L. (1980). Direction of effect in socialization: A comparison of the parent's versus the child's behavior as determinants of disciplinary techniques. Developmental Psychology, 16, 1-9. https://doi.org/10.1037/00121649.16.1.1

Guidroz, A. M., Burnfield-Geimer, J. L., Clark, O., Schwetschenau, H. M., \& Jex, S. M. (2010). The Nursing Incivility Scale: Development and validation of an occupation-specific measure. Journal of Nursing Measurement, 18, 176-200. Retrieved from: https://www.ncbi.nlm.nih.gov/m/pubmed/21290924/

Health Resources and Services Administration. (2010). The registered nurse population: Findings from the 2008 national sample survey of registered nurses. Washington, 
DC: U.S. Department of Health and Human Services. Retrieved from:

https://bhw.hrsa.gov/sites/default/files/bhw/nchwa/rnsurveyfinal.pdf

Henderson, A. (2001). Emotional labor and nursing: An under-appreciated aspect of caring work. Nursing Inquiry, 8, 130-138. Retrieved from:

https://www.ncbi.nlm.nih.gov/pubmed/11882211

Hewlin, P. F. (2003). And the award for best actor goes to...: Facades of conformity in organizational settings. Academy of Management Review, 28, 633-642. https://doi.org/10.2307/30040752

Hochschild, A. R. (2012). The managed heart: Commercialization of human feeling (3rd ed). Berkeley, C.A.: University of California Press.

Hülsheger, U. R., \& Schewe, A. F. (2011). On the costs and benefits of emotional labor: a meta-analysis of three decades of research. Journal of Occupational Health Psychology, 16, 361-389. https://doi.org/10.1037/a0022876

Hutchinson, M., Vickers, M. H., Wilkes, L., \& Jackson, D. (2009). “The worse you behave, the more you seem, to be rewarded": Bullying in nursing as organizational corruption. Employee Responsibilities and Rights Journal, 21, 213-229. https://doi.org/10.1007/s10672-009-9100-z

Hutchinson, M., Wilkes, L., Jackson, D., \& Vickers, M. H. (2010). Integrating individual, work group and organizational factors: testing a multidimensional model of bullying in the nursing workplace. Journal of Nursing Management, 18, 173-181. https://doi.org/10.1111/j.1365-2834.2009.01035.x 
Johnson, H.-A. M., \& Spector, P. E. (2007). Service with a smile: Do emotional intelligence, gender, and autonomy moderate the emotional labor process? Journal of Occupational Health Psychology, 12, 319-333. https://doi.org/10.1037/1076-8998.12.4.319

Katrinli, A., Atabay, G., Gunay, G., \& Cangarli, B. G. (2010). Nurses' perceptions of individual and organizational political reasons for horizontal peer bullying. Nursing Ethics, 17, 614-627. https://doi.org/10.1177/0969733010368748

Kruml, S. M., \& Geddes, D. (2000). Exploring the dimensions of emotional labor: The heart of Hochschild's work. Management Communication Quarterly, 14, 8-49. https://doi.org/10.1177/0893318900141002

Landivar, L. C. (2013). Men in nursing occupations: American community survey highlight report (pp. 1-7). Suitland, MD: U.S. Census Bureau. Retrieved from https://www.census.gov/content/dam/Census/library/workingpapers/2013/acs/2013_Landivar_02.pdf.

Lee, S. (2015). Self-rated health in health surveys. In T. P. Johnson (Ed.), Handbook of health survey methods. Hoboken, N.J.: John Wiley \& Sons, Inc.

Lim, S., \& Lee, A. (2011). Work and nonwork outcomes of workplace incivility: Does family support help? Journal of Occupational Health Psychology, 16, 95-111. https://doi.org/10.1037/a0021726

Maddox, G. L., \& Douglass, E. B. (1973). Self-assessment of health: A longitudinal study of elderly subjects. Journal of Health and Social Behavior, 14(1), 87-93. Retrieved from https://www.ncbi.nlm.nih.gov/pubmed/4708417 
Mann, S., \& Cowburn, J. (2005). Emotional labour and stress within mental health nursing. Journal of Psychiatric and Mental Health Nursing, 12, 154-162. https://doi.org/10.1111/j.1365-2850.2004.00807.x

Martin, L. L., \& Tesser, A. (1996). Some ruminative thoughts. In R.S. Wyer, Jr. (Ed.), Advances in social cognition, Vol. 9. Ruminative thouhgts (pp. 1-47). Hillsdale, N.J.: Lawrence Erlbaum Associates, Inc.

Maslach, C., \& Jackson, S. E. (1984). Burnout in organizational settings. Applied Social Psychology Annual, 5, 133-153. Retrieved from http://psycnet.apa.org/record/1985-24012-001

Maslach, C., \& Jackson, S. E. (1981). The measurement of experienced burnout. Journal of Occupational Behavior, 2, 99-113. https://doi.org/10.1002/job.4030020205

Maslach, C., Schaufeli, W. B., \& Leiter, M. P. (2001). Job burnout. Annual Review of Psychology, 52, 397-422. https://doi.org/10.1146/annurev.psych.52.1.397

Mitchell, D., \& Smith, P. (2003). Learning from the past: Emotional labour and learning disability nursing. Journal of Learning Disabilities, 7(2), 109-117. DOI: $10.1177 / 1469004703007002002$

Morris, J. A., \& Feldman, D. C. (1996). The dimensions, antecedents, and consequences of emotional labor. Academy of Management Review, 21, 986-1010. https://doi.org/10.5465/AMR.1996.9704071861

Mossey, J. M., \& Shapiro, E. (1982). Self-rated health: A predictor of mortality among the elderly. American Journal of Public Health, 72, 800-808. Retrieved from https://www.ncbi.nlm.nih.gov/pubmed/7091475 
Pennebaker, J. W. (1990). Opening up: The healing power of confiding in others (1st ed.). New York, N.Y.: W. Morrow.

Porath, C., Spreitzer, G., Gibson, C., \& Garnett, F. G. (2012). Thriving at work: Toward its measurement, construct validation, and theoretical refinement. Journal of Organizational Behavior, 33, 250-275. https://doi.org/10.1002/job.756

Rafaeli, A., \& Sutton, R. I. (1987). Expression of emotion as part of the work role. Academy of Management Review, 12, 23-37. https://doi.org/10.5465/AMR.1987.4306444

Reich, T. C., \& Hershcovis, M. S. (2015). Observing workplace incivility. Journal of Applied Psychology, 100, 203-215. http://dx.doi.org/10.1037/a0036464

Richards, J. M., \& Gross, J. J. (1999). Composure at any cost? The cognitive consequences of emotion suppression. Personality and Social Psychology Bulletin, 25, 1033-1044. https://doi.org/10.1177/01461672992511010

Roberts, S. J. (1983). Oppressed group behavior: Implications for nursing. Advances in Nursing Science, 5(4), 21-30. Retrieved from: https://www.ncbi.nlm.nih.gov/pubmed/6410980

Rosenstein, A. H., \& O’Daniel, M. (2005). Disruptive behavior and clinical outcomes: Perceptions of nurses and physicians. The American Journal of Nursing, 105(1), 54-64. Retrieved from: http://www.physiciandisruptivebehavior.com/admin/articles/5.pdf 
Rowe, M. M., \& Sherlock, H. (2005). Stress and verbal abuse in nursing: Do burned out nurses eat their young? Journal of Nursing Management, 13, 242-248. https://doi.org/10.1111/j.1365-2834.2004.00533.x

Simons, S. (2008). Workplace bullying experienced by Massachusetts registered nurses and the relationship to intention to leave the organization. Advances in Nursing Science, 31(2), E48-59. https://doi.org/10.1097/01.ANS.0000319571.37373.d7

Simons, S. R., \& Mawn, B. (2010). Bullying in the workplace--a qualitative study of newly licensed registered nurses. Official Journal of the American Association of Occupational Health Nurses, 58, 305-311. https://doi.org/10.3928/0891016220100616-02

Sliter, M., Jex, S., Wolford, K., \& McInnerney, J. (2010). How rude! Emotional labor as a mediator between customer incivility and employee outcomes. Journal of Occupational Health Psychology, 15, 468-481. https://doi.org/10.1037/a0020723

Sliter, M., Sliter, K., \& Jex, S. (2012). The employee as a punching bag: The effect of multiple sources of incivility on employee withdrawal behavior and sales performance. Journal of Organizational Behavior, 33, 121-139. https://doi.org/10.1002/job.767

Sliter, M., Withrow, S., \& Jex, S. (2014). It happened, or you thought it happened? Examining the perception of workplace incivility based on personality characteristics. International Journal of Stress Management, 22(1), 24. http://dx.doi.org/10.1037/a0038329 
Spence Laschinger, H. K., Leiter, M., Day, A., \& Gilin, D. (2009). Workplace

empowerment, incivility, and burnout: Impact on staff nurse recruitment and retention outcomes. Journal of Nursing Management, 17, 302-311.

http://dx.doi.org/10.1111/j.1365-2834.2009.00999.x

Subramanian, S., Huijts, T., \& Avendano, M. (2010). Self-reported health assessments in the 2002 World Health Survey: How do they correlate with education? Bulletin of the World Health Organization, 88, 131-138.

https://doi.org/10.2471/BLT.09.067058

Tedeschi, J. T., \& Felson, R. B. (1994). Violence, aggression \& coercive actions (1st ed). Washington, D.C.: American Psychological Association.

Thomas, S. (2003). Horizontal hostility: Nurses against themselves: How to solve this threat to retention. American Journal of Nursing, 103(10), 87-91. Retrieved from https://works.bepress.com/sandra_thomas/33/.

Trickett, P. K., \& Kuczynski, L. (1986). Children's misbehaviors and parental discipline strategies in abusive and nonabusive families. Developmental Psychology, 22, 115-123. Retrieved from: http://psycnet.apa.org/buy/1986-12115-001

Totterdell, P., \& Holman, D. (2003). Emotion regulation in customer service roles: Testing a model of emotional labor. Journal of Occupational Health Psychology, $8,55-73$. http://dx.doi.org/10.1037/1076-8998.8.1.55

van Katwyk, P. T., Fox, S., Spector, P. E., \& Kelloway, E. K. (2000). Using the JobRelated Affective Well-Being Scale (JAWS) to investigate affective responses to 
work stressors. Journal of Occupational Health Psychology, 5, 219-230.

https://doi.org/http://dx.doi.org/10.1037/1076-8998.5.2.219

Verbrugge, L. M., \& Ascione, F. J. (1987). Exploring the iceberg: Common symptoms and how people care for them. Medical Care, 25, 539-569. Retrieved from: https://www.researchgate.net/publication/19465597_Exploring_the_iceberg_Com mon_symptoms_and_how_people_care_for_them

Wilson, B. L., Diedrich, A., Phelps, C. L., \& Choi, M. (2011). Bullies at work: the impact of horizontal hostility in the hospital setting and intent to leave. The Journal of Nursing Administration, 41, 453-458.

https://doi.org/10.1097/NNA.0b013e3182346e90

Winstanley, S., \& Whittington, R. (2002). Anxiety, burnout and coping styles in general hospital staff exposed to workplace aggression: A cyclical model of burnout and vulnerability to aggression. Work \& Stress, 16, 302-315.

https://doi.org/10.1080/0267837021000058650

Yang, F.-H., \& Chang, C.-C. (2008). Emotional labour, job satisfaction and organizational commitment amongst clinical nurses: A questionnaire survey. International Journal of Nursing Studies, 45, 879-887. https://doi.org/10.1016/j.ijnurstu.2007.02.001

Zhou, Z. (2014). Effects of workplace incivility on nurses' emotions, well-being, and behaviors: A longitudinal study. (Unpublished doctoral dissertation). University of South Florida, Tampa, F.L. Retrieved from http://scholarcommons.usf.edu/etd/5338/ 


\title{
Appendix
}

\author{
Study Measures
}

\section{The Nursing Incivility Scale (NIS)}

Guidroz, Burnfield-Geimer, Clark, Schwetschenau, and Jex (2010)

On a scale of 1 (agree not at all) to 5 (strongly agree), indicate the extent to which you agree with the following statements.

General Incivility: Inappropriate Jokes

1. People make jokes about minority groups.

2. People make jokes about religious groups.

3. Employees make inappropriate remarks about one's race.

4. Employees make inappropriate remarks about one's gender.

5. Employees make inappropriate remarks about one's sexual orientation.

General Incivility: Hostility and Rudeness

6. Employees raise their voices when they get frustrated.

7. People blame others for their mistakes or offense.

8. Basic disagreements turn into personal or verbal attacks on other employees.

9. Some people take things without asking.

10. Employees don't stick to an appropriate noise level (e.g., talking too loudly).

11. Employees display offensive body language (e.g., crossed arms, body posture). Nurse Incivility: Inconsiderate Behavior

12. Nurses argue with each other frequently.

13. Nurses have violent outbursts or heated arguments in the workplace.

14. Nurses scream at other employees.

Nurse Incivility: Gossip and Rumors

15. Nurses gossip about one another.

16. Nurses gossip about their supervisor at work.

17. Nurses bad-mouth others in the workplace.

18. Nurses spread bad rumors around here.

Nurse Incivility: Free-Riding

19. Nurses make little contribution to a project but expect to receive credit for working on it.

20. Nurses claim credit for my work.

21. Nurses take credit for work they did not do.

Supervisor Incivility

22. My supervisor is verbally abusive. 
23. My supervisor yells at me about matters that are not important.

24. My supervisor shouts or yells at me for making mistakes.

25. My supervisor takes his/her feelings out on me (e.g., stress, anger, "blowing off steam".

26. My supervisor does not respond to my concerns in a timely manner.

27. My supervisor factors gossip and personal information into personnel decisions.

28. My supervisor is condescending to me.

Physician Incivility

29. Some physicians are verbally abusive.

30. Physicians yell at nurses about matters that are not important.

31. Physicians shout or yell at me for making mistakes.

32. Physicians take their feelings out on me (e.g., stress, anger, "blowing off steam").

33. Physicians do not respond to my concerns in a timely manner.

34. I am treated as though my time is not important.

35. Physicians are condescending to me.

Patient/Visitor Incivility

36. Patients do not trust the information I give them and ask to speak with someone of higher authority.

37. Patients are condescending to me.

38. Patients make comments that question the competence of nurses.

39. Patients criticize my job performance.

40. Patients make personal verbal attacks against me.

\section{Emotional Labor Scale - Surface Acting Subscale}

Brotheridge and Lee (2003)

On a scale of 1 (never) to 5 (always), indicate how frequently at work you engage in the following behaviors.

1. Resist expressing your true feelings.

2. Pretend to have emotions you don't really have.

3. Hide your true feelings about a situation.

\section{Pittsburgh Sleep Quality Index}

Buysse, Reynolds, Monk, Berman, and Kupfer (1989)

Indicate your response to the following item on a scale from 1 (very bad) to 10 (very good).

1. How would you evaluate last night's sleep? 


\section{Sleep Items Developed for the Study}

1. How many hours did you sleep last night?

Reflect back on last night's sleep and indicate your agreement with the following items on a scale from 1 (agree not at all) to 7 (strongly agree).

2. I had trouble staying asleep (including waking up too early).

3. I had trouble falling asleep.

4. I woke up after my usual amount of sleep feeling tired and worn out.

5. I woke up several times during the night.

\section{Job-Related Affective Well-Being Scale}

Van Katwyk, Fox, Spector, and Kelloway (2000)

Please rate the extent to which you are experiencing the following right now on a scale from 1 (not at all) to 5 (very much).

1. Depressed

2. Discouraged

3. Gloomy

4. Fatigued

5. Calm

6. Content

7. Relaxed

8. At ease

9. Ecstatic

10. Excited

11. Energetic

12. Enthusiastic

13. Furious

14. Frightened

15. Angry

16. Anxious

\section{Emotional Exhaustion Items}

Please rate the extent to which you are experiencing the following right now, on a scale from 1 (not at all) to 5 (very much).

Thriving at Work Scale (Porath, Spreitzer, Gibson, \& Garnett, 2012) 
1. I feel alert and awake. (R)

2. I feel alive and vital. (R)

3. I feel energized. (R)

Maslach Burnout Inventory (Maslach \& Jackson, 1981)

4. I feel emotionally drained.

5. I feel used up.

6. I feel burned out. 